\title{
New Neotropical Nepticulidae (Lepidoptera) from the western Amazonian rainforest and the Andes of Ecuador
}

\section{RIMANTAS PUPLESIS}

Department of Zoology, Vilnius Pedagogical University, 39, Studentu str., Vilnius 2004 LT, Lithuania

\section{ARŪNAS DIŠKUS}

Department of Zoology, Vilnius Pedagogical University, 39, Studentu str., Vilnius 2004 LT, Lithuania

\section{GADEN S. ROBINSON}

Department of Entomology, The Natural History Museum, Cromwell Road, London SW7 5BD, UK

\section{CONTENTS}

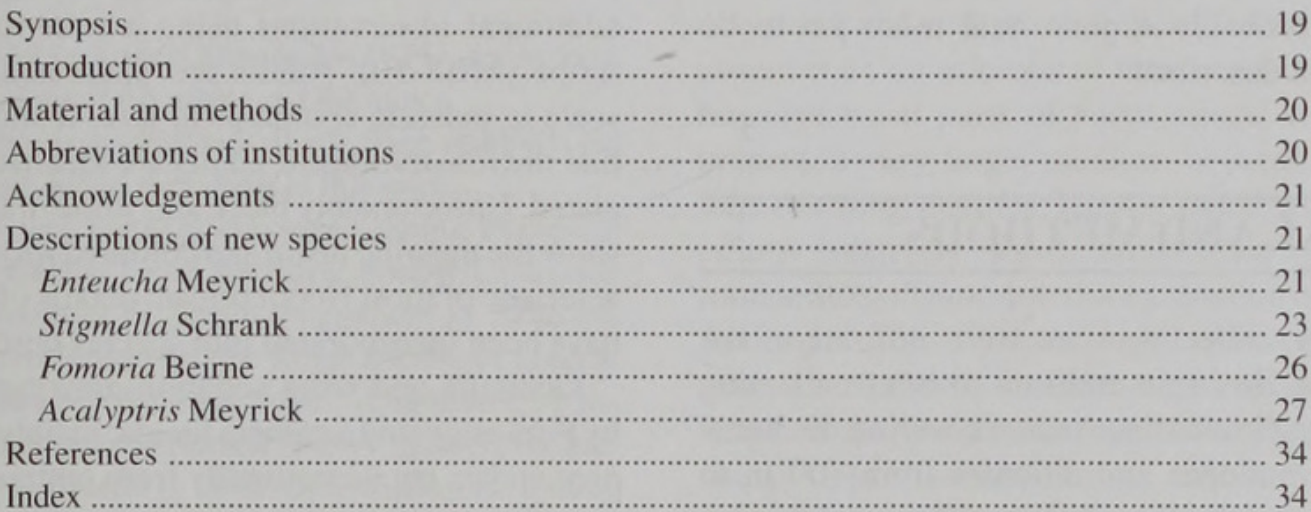

SYNOPSIS. Fieldwork in 2000-2001 in the upper Amazon basin and the Andes (Ecuador) has yielded 16 new species of Nepticulidae, described here. Four genera are represented: Enteucha Meyrick (two species: E. acuta, E. guajavae), Stigmella Schrank (four species: S. montanotropica, $S$. nubimontana, S. rubeta, S. austroamericana), Fomoria Beirne (two species: F. repanda, $F$. tabulosa) and Acalyptris Meyrick ( 8 species: A. ecuadoriana, A. onorei, A. basihastatus, A. pseudohastatus, A. articulosus, A. rotundus, A. amazonius, A. insolentis); the authors of all new taxa are Puplesis \& Diškus. Larvae have been reared from three genera of different plant families: Psidium (Myrtaceae), Acalypha (Euphorbiaceae) and Rubus (Rosaceae). The adult moths of all 16 species treated are illustrated in black and white, with line drawings of genitalia and, for four species, drawings of leaf-mines.

\section{INTRODUCTION}

Nepticulidae are a very specialized, isolated family of primitive monotrysian Microlepidoptera with a worldwide distribution and about 750 described species.
Description of the Neotropical fauna began in the late 19th and early 20th century with descriptions of species by Zeller (1877) and Meyrick (1915, 1931). Further species were described by Forbes \& Leonard (1930), Bourquin (1962), Davis (1978, 1984, 1985), Wilkinson (1981) and Newton \& Wilkinson (1982). A consider- 
able boost was given to the number of species known from the Neotropical region by Puplesis \& Robinson (2000) who described as new 33 species, mostly from Belize.

In this paper we report upon the results of fieldcollecting by Rimantas Puplesis (VPU) and Simon R. Hill (UW) in 2000-2001 in the upper Amazon basin and the Andes of Ecuador, areas unrepresented among material reviewed by Puplesis \& Robinson (2000). From these new collections we describe below 16 new species - a significant addition to our knowledge of the Amazonian and Andean nepticulids - and provide larval rearing data from three host genera in different plant families.

This ongoing collaborative project (for previous publications, see Puplesis \& Robinson, 1999; 2000) was undertaken at the Natural History Museum, London with the support of the Royal Society (London) and Professor Hering Memorial Fund. It combines Robinson's interests in Microlepidoptera biodiversity with Puplesis's and Diškus's expertise and interest in inventorying the families of primitive Microlepidoptera. We hope that further documentation of the Neotropical fauna and illustration of newly discovered species will stimulate further studies of the Nepticulidae of South America; we are very conscious that there is probably a great deal more yet to be discovered and described.

\section{MATERIAL AND METHODS}

Three primary collecting-sites were utilized in the upper Amazon Basin, in addition to brief collecting trips within the Ecuadorian Andes, covering the western and eastern slopes and altitudes from $700 \mathrm{~m}$ to $4200 \mathrm{~m}$. Primary sites were: the Yasuni Research Station (Napo Region, SE of Coca, rainforest at $260 \mathrm{~m}$, $76^{\circ} 36^{\prime} \mathrm{W}, 00^{\circ} 38^{\prime} \mathrm{S}$ ) and Jatun Sacha Biological Station and Misahualli (both localities in Napo Region, SE of Tena, premontane tropical forest at $400-500 \mathrm{~m}$, $77^{\circ} 36^{\prime} \mathrm{W}, 01^{\circ} 04^{\prime} \mathrm{S}$ ).

Two main collecting methods were used: mining larvae were collected and reared, and adults were collected at light. Mined leaves (or other plant parts) were placed in Petri dishes which were then checked regularly for emerged adults. Emergence occurred within 1-3 weeks. Adult moths were collected by attracting them to mercury-vapour light from a lamp suspended slightly above eye-level and $5-10 \mathrm{~cm}$ in front of a white screen, rather closer than is usual in the standard method for light-collecting (described by Robinson et al., 1994) in which the lamp is about $0.5 \mathrm{~m}$ from the illuminated surface. A portable Honda EX 350 generator was used as a power-source. As many different habitats and sites as possible were sampled.
Moths attracted to the screen were collected into small glass tubes and pinned after killing with ethyl acetate vapour.

Genitalia were prepared following the method described by Robinson (1976). After maceration of the abdomen in $10 \% \mathrm{KOH}$ and subsequent cleaning, male genital capsules were removed from the abdomen and mounted ventral side uppermost. In cases of complicated armature, the genitalia were studied and sketched in glycerin before fixation. The aedeagus was removed from and mounted alongside the genital armature. Female genitalia were removed entirely from the abdomen, cleaned and mounted ventral side uppermost. Genitalia and abdominal pelts of both sexes were stained with Chlorazol Black (Direct Black 38/Azo Black) and mounted in Euparal.

Forewing length is expressed as a range, where availability of material made this possible, measured along the costa from the wing base to the apex of the cilia. Wingspan was measured from the tip of the left wing to the tip of the right wing, where well-mounted specimens were available; in other cases the forewing length was doubled and the thorax width added.

Illustrations of the adults and leaf-mines were made in Indian ink by Mr Arturas Skorupskas (VPU) using preliminary sketches and notes by R. Puplesis and with additional observations using a stereoscopic microscope (MBS-10). Adults are illustrated at the same scale to indicate comparative size. It should be noted that the illustrations of adults are idealized and generalized. Unfortunately black and white drawings cannot show the metallic lustre and coloured iridescence characteristic of most Nepticulidae; details of such colours have been incorporated into species descriptions.

Genitalia and wing venation drawings were made by Puplesis using a camera lucida, mainly from permanent slides, but occasionally from temporary glycerin mounts.

Depositories of types are given in the species descriptions: either BMNH - The Natural History Museum, London, UK (formerly British Museum (Natural History)) or VPU - Vilnius Pedagogical University, Vilnius, Lithuania.

\section{ABBREVIATIONS OF INSTITUTIONS}

BMNH The Natural History Museum, London, UK (formerly British Museum (Natural History))

INEFAN Instituto Ecuatoriano Forestal de Areas Naturales y Vida Silvestre, Ecuador

NNM Nationaal Natuurhistorisch Museum (Naturalis), Leiden, Netherlands

PUCE Pontificia Universidad Católica del Ecuador, Quito, Ecuador

VPU Vilnius Pedagogical University, Vilnius, Lithuania 
USNM National Museum of Natural History, Washington DC, USA (formerly United States National Museum)

UW University of Westminster, London, UK

ZMUC Zoologisk Museum, University of Copenhagen, Copenhagen, Denmark

ACKNOWLEDGEMENTS. Mr Ole Karsholt and Prof. Niels P. Kristensen (ZMUC) provided the initial stimulus for the present project together with generous support during its course.

Mr Simon R. Hill (UW) is thanked for his selfless and generous help with planning fieldwork, transport of equipment, technical assistance and companionship during the Ecuador collecting-trips in 2000 and 2001.

We are extremely grateful to Dr Giovanni Onore (PUCE) for all necessary preparations for a study permit to collect material in Ecuador and for scientific collaboration. Special thanks are due to Miss Ruth Boada and Miss Palma Lucy Elizabeth Baldeón (PUCE) for their generous help and friendliness during Puplesis's and Hill's fieldwork in Ecuador. We thank botanists Jaime Jaramillo A. and David Padilla Z. (PUCE) for the identification of numerous host-plant samples collected in Ecuador. Our very special thanks extend to botanist Alvaro Javier Pérez (PUCE), who kindly, efficiently and very professionally assisted us during the last stage of this project.

We are grateful to Artūras Skorupskas (VPU) for making Indian-ink drawings of the adults and the mines.

The first author is grateful to Kevin R. Tuck (BMNH) for generous support during the course of this work.

This project was partially conducted during Puplesis's study visits to BMNH under the Royal Society/Lithuanian Academy of Sciences Exchange Programme in 2000 and 2001. We are most grateful to the Royal Society of London and Professor Hering Memorial Fund (administered by the British Entomological and Natural History Society) for support. We are very grateful to INEFAN (Ecuador) for a study permit to collect in Ecuador. Puplesis thanks the Trustees and the Keeper of Entomology at The Natural History Museum, London, for study facilities and access to collections. We thank Kevin Tuck, Malcolm Scoble and an anonymous reviewer for refereeing this paper, and for their perceptive and useful suggestions.

\section{DESCRIPTIONS OF NEW SPECIES}

For generic diagnoses and synonymy, see Puplesis \& Robinson (2000).

\section{ENTEUCHA Meyrick}

\section{Enteucha acuta Puplesis \& Diškus sp. n.}

(Figs 4, 26-28)
MALE(Fig. 4). Forewing length: about $1.6 \mathrm{~mm}$. Wingspan: about 3.4-3.5 mm. Head: palpi brownish cream; frontal tuft ochreous [heavily rubbed in the single available example]; collar probably cream [totally rubbed off in the available specimen]; eyecaps cream, large; antenna brown, comprising of about 17-18 segments. Thorax, tegulae and forewing brown; area of forewing before and after fascia dark brown; fascia postmedial, shining silver, very distinctive, perpendicular to forewing. Cilia grey. Underside of forewing brown or brownish. Hindwing lanceolate, brownish grey; its cilia concolorous. No androconia on forewing or hindwing. Legs brownish cream, darkened with fuscous brown on upperside. Abdomen brown on upperside, paler on underside.

FEMALE. Unknown.

GENITALIA ơ(Figs 26-28). Capsule 230-233 m long. Tegumen band-like, laterally slightly extended into papillated sublateral lobes. Uncus triangular with single, well-sclerotized caudal papilla. Gnathos with large posterior process and triangular lateral arms; central plate weakly developed, in shape of narrow band; anterior processes apparently absent or as tiny anterior papillae only. Valva 160-170 $\mu \mathrm{m}$ long; slender, curved inwardly, with broader basal one-quarter to one-third, and with pointed apex. Transtilla apparently absent (i.e., no sclerotized transverse bar developed), however basal parts of valva joined ventrally. Juxta present, a very large, medium or weakly sclerotized lobe reaching gnathos, basally fused with valva. Vinculum relatively short, constricted and smoothly rounded distally; no anterior excavation or lateral lobes. Aedeagus $165-170 \mu \mathrm{m}$ long, with one very large cornutus and two smaller ones one-quarter or less length of major cornutus; apex of aedeagus with small sharp denticles and long, slender, cornuti-like sclerotized wrinkles.

BIOLOGY. Single adult collected in January.

DIAGNOSIS. Distinctive species; among all currently known species of the genus strongly differing by the presence of a large cornutus. In external features, particularly the fascia, it bears a superficial resemblance to the Neotropical gilvafascia (Davis) and snaddoni Puplesis \& Robinson; however the fascia of the new species is shining silver, and there is no white apical spot on the forewing.

\section{DistribUtion. Lowland Amazon rainforest} (Ecuador).

CONDITION OF TYPE MATERIAL. The single specimen is badly pinned, the head is rubbed, however the wings are well preserved with clear patterning.

MATERIAL EXAMINED. Holotype $\sigma^{*}$ : Ecuador: Napo Region, SE of Coca, near Rio Tiputini, Yasuni National 
Park, 260 m, 15-25.i.2000 (Puplesis \& Hill) genitalia slide no. 29604 (BMNH).

REMARKS. This remarkable species represents the first member of the genus to be found in Amazonia, and it is described from only a single specimen because of the very distinct characters of the genitalia, which exhibit considerable apomorphic modification in comparison with other related species.

\section{Enteucha guajavae Puplesis \& Diškus sp. n.}

(Figs 2, 3, 20-25, 89, 90, 100, 101)

MALE (Fig. 3). Forewing length: 1.4-1.6 mm. Wingspan: 3.1-3.6 mm. Head: palpi brownish cream; frontal tuft ochreous orange; collar cream and paired; eyecaps cream and glossy; antenna fuscous on upperside and grey on underside, comprising of about 21-24 segments. Thorax and tegulae fuscous with some purple iridescence; forewing of same colour, with two striking shiny silvery fasciae: basal fascia almost half width of postmedial. Cilia greyish with distinct cilia-line. Underside of forewing fuscous. Venation with Sc, four radials, one medial, but no cubital vein (Fig. 2). Hindwing lanceolate, covered with brownish cream androconial scales (especially dense on underside of wing, making the hindwing the same colour as the underside of the abdomen); cilia of hindwing grey. Legs brownish cream, darkened with fuscous brown on upperside. Abdomen fuscous on upperside but ochreous cream on underside.

FEMALE. Hindwing grey. Otherwise as in male.

Genitalia ơ (Figs 20-25). Capsule 317-285 $\mu \mathrm{m}$ long. Tegumen band-like, distally widely rounded. Uncus with two short but broad papillated lateral lobes. Gnathos in shape of inverted ' $v$ '; caudally directed part weakly sclerotized and rounded; lateral arms very slender. Valva 140-155 $\mu \mathrm{m}$ long; slender, curved inwardly, with broader and strongly sclerotized basal one-quarter to one-third and with pointed apex. Distinct transtilla apparently absent; however, a weakly sclerotized transverse bar is evident between basal processes of valvae; valvae additionally connected ventrally by ventral sclerite which is fused with vinculum plate. Juxta weakly developed and without clearly defined shape. Vinculum very long and widely rounded distally; no anterior excavation or lateral lobes; caudally directed lateral arms of vinculum strongly sclerotized and therefore distinct (in contrast to many other nepticulids). Aedeagus a little longer than vinculum plate, $195-230 \mu \mathrm{m}$ long, with small pointed lateral extension at the caudal end and with a few (4-5) compactly arranged cornuti; cornuti resemble the 'usual' spine-like ones common in many nepticulids; however, in this species they are weakly defined, sometimes with unsclerotized apices.
GENITALIA + (Figs 89, 90). Total length about 305$365 \mu \mathrm{m}$. Abdominal tip widely rounded, anal papillae indistinct. Apophyses anteriores distally with longer and narrow lateral process and large blunt inner lobe. Apophyses posteriores slender and much exceeding apophyses anteriores. Ductus spermathecae originating from a heavily sclerotized and wrinkled area between apophyses posteriores, narrow and long, with three sclerotized convolutions. Corpus bursae weakly folded, relatively very small, distinctly globular, with an oval signum formed by a group of numerous, large, blunt pectinations.

Biology (Figs 100, 101). Host-plant: Psidium guajava L. (Myrtaceae). Larvae green, found in January; mining leaves. Egg on underside of leaf. Mine slender, sinuous, from short to relatively long, mainly on upperside of leaf. In the first half of the mine blackish frass can fill most of the width, with narrow but still distinct clear margins remaining; in the second half of the mine frass is deposited as a black narrow central line with broad clear margins remaining; sometimes the central line of frass can be interrupted, but in most examples it forms an uninterrupted line. Cocoon greyish ochreous, flattened, strongly narrowed to the posterior end, ca. 2.5 by $1.5 \mathrm{~mm}$. Voltinism of the species is not known. Mining larvae in January were found together with old and very old mines from probably November-December. Adults from larvae collected in January emerged after 20-25 days (in February). The new species seems quite common on cultivated guava in Ecuador.

DiAGNOSIS. Very distinctive species; from all currently known species of this genus (and most species of other genera) it differs strongly by the presence of two distinctive forewing fasciae. In the male genitalia this species is easily distinguishable by the shape of the gnathos (an inverted ' $v$ '). In the female genitalia it differs from other Enteucha by the oval signum formed by a group of numerous, large, blunt pectinations. The unusual host-plant may also make this species distinctive, but as very little is known about the biology of other Enteucha it is uncertain how atypical the utilisation of Myrtaceae might be.

Distribution. Western foothills of the Andes (Ecuador), but probably with a much wider distribution. Common in the Bucay area ( $80 \mathrm{~km} \mathrm{E}$ of Guayaquil) (Fig. 101).

CONDITION OF TYPE MATERIAL. A few paratype specimens from the type series containing 8 specimens of this minute species are badly pinned.

Material examined. Holotype $\sigma^{\star}$, Ecuador: 80 $\mathrm{km}$ E of Guayaquil, Bucay, western foothills of Andes, $700 \mathrm{~m}$, premontane tropical forest and orchards, 1619.i.2001 (Puplesis \& Hill), genitalia slide AD0340 
(VPU). Paratypes, $5 \sigma^{\star}$, data as holotype, genitalia slides AD0341, AD0342, (VPU)], 2\%, genitalia slides AD0343, AD0344, forewing venation slide AD0346 (VPU)]. Mines no. 4722-VPU.

\section{STIGMELLA Schrank}

\section{Stigmella montanotropica Puplesis \& Diškus sp. $n$.}

(Figs. 5, 29, 30, 91, 98, 99, 102)

MALE. See Remarks.

Female (Fig. 5). Forewing length: $2.2-2.4 \mathrm{~mm}$. Wingspan: $5.0-5.1 \mathrm{~mm}$. Head: palpi cream; frontal tuft from pale orange to bright orange; collar forming two clearly separated tufts of cream coloured lamellar scales; eyecaps cream; antenna fuscous, comprised of 22 segments. Thorax, tegulae and forewings fuscous brown with some bronzy-golden and purple reflection. Cilia dark grey to fuscous. Underside of forewing fuscous with some indistinct bronze-golden and purple reflection. Hindwing lanceolate, dark brown; cilia concolorous. Legs dark fuscous grey, distally cream. Abdomen fuscous, shiny, with long anal tufts.

Genitalia $\sigma^{*}$ (Figs 29, 30). Capsule 250-260 $\mu \mathrm{m}$ long. Uncus strongly sclerotized, constricted towards distal end, with four slender and distinct distal papillae. Tegumen very short, simple, band-like. Gnathos with large medially narrowed central plate and two very slender and long posterior processes parallel with each other; anterior extensions of gnathos triangularly lobate, weakly developed; lateral arms of gnathos narrowing caudally, relatively very short. Valva 144-151 $\mu \mathrm{m}$ long, constricted at apex and with two closely spaced and pointed apical processes. Transtilla with inwardly curved transverse bar, broad triangular angles but without sublateral processes. Ventral plate of vinculum relatively short, one-half or more of length of valva; anterior excavation wide but shallow, lateral lobes small, distally pointed. Aedeagus broad $(90-100 \mu \mathrm{m})$ and relatively short (212-218 $\mu \mathrm{m}$ long). Vesica with 14 large or very large horn-like cornuti, the largest apical. Juxta apparently absent.

GENITALIA + (Fig. 91). Total length about $1125 \mu \mathrm{m}$. Anal papillae weakly developed, two widely rounded but very short setose lobes. Apophyses anteriores gradually tapering distally, straight. Apophyses posteriores very slender and long, their distal ends slightly exceeding apophyses anteriores. Accessory sac globular, wrinkled, with slender, medium to weakly sclerotized ductus spermathecae, its inner duct with about nine neatly arranged convolutions. Corpus bursae large, oval, with a semicircular signum comprising very numerous pectinations; proximal part of corpus bursae long and strongly folded.
BioloGY (Figs 98, 99, 102). Host-plant: Acalypha sp. (Euphorbiaceae). Larvae in January-February, mining leaves. Egg on upperside or underside of leaf, usually deposited close to a small leaf-vein. Mine very long, slender, sinuous to contorted, mainly on upperside of leaf, more than $100 \mathrm{~mm}$ in straightened length. In the first half of the mine dark brown or blackish frass may fill up the entire width of the mine, latterly deposited in arcuate waves with or without leaving narrow, clear margins to the mine; the longest, final stage of the mine is usually with a broad trace of black granulated frass, leaving clear margins. Cocoon whitish, oval, flattened, strongly narrowed to the posterior end, ca. 2.5 by $1.5 \mathrm{~mm}$. Voltinism not known. Mining larvae in early February were found together with old and very old mines from probably November-January. Currently adults are known from February-early March.

DiAGNOSIS. Belongs to the $S$. salicis-group (see Puplesis, Diškus, Robinson \& Onore, 2002). Easily recognisable among all other species of the group by the combination of smoothly scaled fuscous forewings (without fascia) with numerous large cornuti in the aedeagus. Among Neotropical representatives of the group, the male genitalia most closely resemble those of andina (Meyrick) and cuprata (Meyrick); however, this species may be distinguished by the uniformly dark forewing and hindwing, and by the shape of the cornuti and the apical processes of the valva.

DisTRIBUTION. Tropical montane forest of the western slopes of the Andes (Ecuador) (Fig. 102); known from altitudes around $1200 \mathrm{~m}$. See also Remarks.

CONDITION OF TYPE MATERIAL. Holotype and especially female paratype in relatively good condition; the male paratype comprises only a genitalia slide (29618 BMNH), the genitalia, fully formed and sclerotized, dissected from a dead pupa.

MATERIAL EXAMINED. Holotype + , Ecuador: E of Santo Domingo de los Colorados, Tandapi, montane tropical forest, $1200 \mathrm{~m}$, larvae on leaves of Acalypha sp. (Euphorbiaceae), 3-6.ii.2000 (Puplesis), genitalia slide no. 29619 (BMNH). Paratypes, data as holotype, $1 \sigma^{7}$ genitalia slide [only - see above] no. 29618 (BMNH), 1 \% , slide AD0336 (VPU). Mines no. 4628 (VPU). See also Remarks.

REMARKS. The description of the external features of this species is based on females.

A few specimens closely resembling this species were reared from Acalypha leaf-mines in 2001 in premontane tropical forest SE of Tena (Misahualli) and montane forest in Baños. These specimens will not be dealt with further until additional material is available; they may represent a closely related but different allopatric new species. The specimens are deposited in VPU (male genitalia slides AD 0345, AD 0347, AD 0348). 


\section{Stigmella nubimontana Puplesis \& Diškus sp. $n$.}

(Figs 6, 31-36, 94, 95)

MALE(Fig. 6). Forewing length: about $2.5 \mathrm{~mm}$. Wingspan: $5.2-5.3 \mathrm{~mm}$. Head: palpi grey-cream; frontal tuft pale orange; collar small, dark brown with some purple reflections; eyecaps cream with strong golden reflection; antenna fuscous, comprising of 29-30 segments. Thorax and tegulae dark brown with golden reflection. Forewing coppery-brown with golden and purple reflection, purple reflection particularly strong along costal margin towards fascia; fascia postmedial, weakly demarcated, comprising coppery-golden shining scales; area behind fascia dark brown with purple iridescence; additionally a slender terminal spot or fascia comprising the same shining, coppery-golden scales as the fascia. Cilia fuscous to grey at distal end. Underside of forewing brown with some purple reflection distally. Hindwing and its cilia brown-grey. No androconia on hindwing or forewing. Legs fuscous, shiny. Abdomen fuscous.

FEMALE. Unknown.

Genitalia ơ (Figs 31-36). Capsule 290-309 $\mu \mathrm{m}$ long. Uncus with shallow distal excavation and almost parallel, strongly sclerotized lateral margins; the structure may vary a little in length. Tegumen small, simple, band-like. Gnathos with very long, slender, parallel caudal processes, narrowed lateral arms and short, wide central plate, gradually constricted at the middle. Valva 168-207 $\mu \mathrm{m}$ long, broad, with two inwardly curved and pointed apical processes; the ventral process blunt, lobe-like. Transtilla with slender transverse bar and almost rounded corners. Juxta apparently absent. Ventral plate of vinculum with large triangular lobes and deep semicircular excavation distally. Aedeagus 195-220 $\mu \mathrm{m}$ long, with many fine spinelike cornuti and three large horn-like ones.

Biology (Figs 94, 95). Host-plant: Rubus sp. (Rosaceae). Larvae are known mining leaves in January-February but the mining period is likely to be much longer. Egg on the underside of leaf, usually deposited close to a leaf-vein. Mine usually between two leaf-veins, a compactly deposited gallery which resembles an elongated blotch, about $2.8-3.8 \mathrm{~cm}$ in straightened length. Beginning of mine slender and filled with dark brown frass; later the gallery widening considerably, the frass dark brown, deposited in a broad compact central line with clear margins; final length of mine very broad (sometimes a blotch), with granulated dark brown frass deposited more or less irregularly or into a relatively slender central line. Final part of mine usually covering beginning of mine, so the initially slender gallery may be impossible to see. Larva yellowish. Cocoon pale brown with some yellowish tint, oval, flattened, gradually narrowed to the posterior end, ca. $2.8-3.0 \times 1.8 \mathrm{~mm}$. Voltinism not known. Numerous mining larvae in early February were found together with very numerous old and very old mines from probably November-January period. Adults known from February-early March.

DiAGNOSIS. Belongs to the S. salicis-group (see Puplesis, Diškus, Robinson \& Onore, 2002); two shining forewing fasciae and the combination of three large cornuti with numerous fine, spine-like cornuti make this a distinctive species of the group. This high Andes species is somewhat similar and related to rubeta, the other Rubus-mining species from montane tropical forest on the western slopes of the Andes; nubimontana differs from rubeta in the more strongly developed fasciae of the forewing, particularly in the unelaborated uncus \& tegumen, and the presence of many fine, spine-like cornuti (in rubeta no tiny cornuti are present). There are some differences in the mines too: the slender beginning of the gallery made by rubeta has a very slender, broken line of blackish frass whereas in mines of nubimontana dark brown frass fills up the entire width of the gallery.

Distribution. Cloud forest of the high Andes (Ecuador), at about $3500 \mathrm{~m}$, where it appears to be very common.

CONDITION OF TYPE MATERIAL. The male holotype is a reared specimen with well-preserved forewings and antennae but with detached hindwings stored in a small gelatine capsule beneath the specimen. The two paratypes came from dead late-stage pupae and are therefore not represented by pinned adults, just by good-quality genitalia preparations, mines and cocoons.

MATERIAL EXAMINED. Holotype $\sigma^{\star}$, Ecuador: Napo Region, Andes, $3500 \mathrm{~m}$, Papallacta, cloud forest, larvae 2-3.ii.2000 on Rubus sp. (Puplesis \& Hill), genitalia slide no. 29614 (BMNH). Paratypes, 20, data as holotype, genitalia slide nos AD0321, AD0322 (VPU). Mines no. 4630 (VPU).

REMARKS. During fieldwork in Ecuador in 2000 very many mining larvae of this species were collected in the Andes (Papallacta). However, for some unknown reason (not parasitism - very few parasitoids were observed), very few adults emerged. Another species mining on the same Rubus sp. at the same time in the same locality was also noticed, and a single female specimen was reared (no. AD0337 VPU). This last species is not included here because of its inadequate representation.

Stigmella rubeta Puplesis \& Diškus sp. n.

(Figs 7, 37-39, 92, 96, 97, 102)

MALE(Fig. 7). Forewing length: about $2.0 \mathrm{~mm}$. Wing- 
span: $4.5 \mathrm{~mm}$. Head: palpi grey-cream or brown-cream; frontal tuft orange; collar small, fuscous; eyecaps cream with some golden reflection; antenna fuscous, number of segments unknown. Thorax and tegulae fuscous with some golden reflection. Forewing fuscous with golden and purple reflections, and without distinct fascia: there are only some shiny silver scales in the usual area of a median-postmedial fascia and at apex of forewing. Cilia fuscous to grey at the distal end. Underside of forewing brown. Hindwing and its cilia dark grey. No androconia on hindwing or forewing. Legs fuscous, distally grey-cream. Abdomen fuscous.

FEMALE. Externally probably very similar to male, however, the single female known came from a dead pupa and therefore the scaling pattern could not be studied.

Genitalia ơ (Figs 37-39). Capsule 290-300 $\mu \mathrm{m}$ long. Uncus elaborate in comparison with related species: the bilobate, deeply divided structure is paralleled by an additional broad dorsal lobe (Fig. 38). Tegumen small, also unusually elaborate, with strongly sclerotized anterior extension distally. Gnathos with very long, slender, parallel caudal processes, narrowed lateral arms and short, wide central plate constricted at middle and with a small anterior papilla. Valva 175$185 \mu \mathrm{m}$ long, broad, with rounded inner lobe of valva (not forming a process as in nubimontana) and with inwardly curved and pointed apical process. Transtilla with slender transverse bar and angular corners. Juxta apparently absent. Ventral plate of vinculum with large triangular lobes and deep semicircular excavation distally. Aedeagus about $200 \mu \mathrm{m}$ long, without small, spine-like cornuti, but with seven large ones: three of them broad-based and four well-sclerotized and slender.

Genitalia + (Fig. 92). Total length about 800$820 \mu \mathrm{m}$. Abdominal tip widely rounded. Apophyses posteriores about $187-225 \mu \mathrm{m}$ long, very slender and straight. Apophyses anteriores slightly longer and broader. Accessory sac globular, wrinkled. Ductus spermathecae membranous, a short section only coiled and strongly sclerotized. Corpus bursae distinctly oval, with numerous pectinations all over the sac; proximal part of corpus bursae narrowed, short and strongly folded.

BioloGy (Figs. 96, 97, 102). Host-plant: Rubus sp. (Rosaceae). Larvae mine leaves in January-February (but the mining period is probably much longer). Egg on underside of leaf, usually deposited close to a leafvein. Mine usually between two leaf-veins, starting as a long and very narrow gallery with blackish or black frass deposited in a broken, slender to very slender central line; later the gallery widening, sometimes very contorted and resembling more a blotch; the blackish (sometimes brown) frass in the wider part of the mine tending to be deposited in a broad, irregular central line. Total length of straightened gallery about 4.2-4.6 $\mathrm{mm}$ (about half of this length belongs to the very slender part of the mine), but the mine does not superficially appear as long, as the slender region is very indistinct; wider part very convoluted, sometimes covering beginning of mine. Larva yellowish. Cocoon pale brownish with some yellowish tints, oval, flattened, gradually narrowed to the posterior end, 2.5-2.6 $\times 1.8 \mathrm{~mm}$. Voltinism not known. Numerous mining larvae were found in early February together with very numerous old and very old mines from probably the November-January period. Adults are known from February-early March.

Diagnosis. Belongs to the S. salicis-group (see Puplesis, Diškus, Robinson \& Onore, 2002); this tropical montane Rubus-mining species is most similar and related to nubimontana, the high-Andean species also feeding on Rubus. Differs from nubimontana by the darker wings, less prominent forewing pattern, the elaborate uncus and tegumen, the absence of very small spine-like cornuti (which are very characteristic for nubimontana) and by the presence of broad-based cornuti on the vesica (which are apparently absent in nubimontana). Additionally, there are some differences in the mines: the slender start of the gallery made by rubeta has a very slender, broken line of blackish frass (Fig. 97) whereas in mines of nubimontana dark brown frass fills the whole width of the gallery (Fig. 95).

DISTRIBUTION. Tropical montane forest of the western slopes of the Andes (Ecuador), at about $1200 \mathrm{~m}$, where it appears to be quite abundant.

MATERIAl EXAMINED. Holotype $\sigma^{*}$, Ecuador: western Andes, E of Santo Domingo de los Colorados, Tandapi, montane tropical forest, larvae 3-6.ii.2000 on Rubus sp. (Puplesis \& Hill), genitalia slide no. 29616 (BMNH). Paratype: $\uparrow$, data as holotype, genitalia slide no. 29617 (BMNH) (Puplesis) (genitalia only - see Remarks). Mines no. 4629 (VPU).

REMARKS. The female specimen mentioned above was taken from a fully-developed pupa, and the paratype is represented only by a preparation of the fully formed and sclerotized genitalia. It appears that rubeta and nubimontana represent two very closely related, allopatric species.

\section{Stigmella austroamericana Puplesis \& Diškus sp. $\mathbf{n}$.}

(Figs 8, 40-43)

MALE (Fig. 8). Forewing length: $1.6-1.7 \mathrm{~mm}$. Wingspan: $3.6-3.8 \mathrm{~mm}$. Head: palpi (and face) whitish cream; frontal tuft pale yellowish orange, collar large, whitish cream; eyecaps whitish cream; antenna of contrasting colour, fuscous on upperside, but distinctly 
cream on underside, comprising of 38 segments. Thorax, tegulae and forewing dark grey-brown irrorated uniformly with grey with strong golden reflection; a few scales just before forewing cilia may appear glossy white when viewed at a certain angle. Cilia grey. Underside of forewing brownish fuscous: fuscoustipped scales densely irrorated grey-cream on grey background. Hindwing and cilia brown-grey. No androconia on forewing or hindwing. Legs brownish cream distally and on underside, elsewhere dark greybrown. Abdomen silver-blackish on upperside, grey, glossy; tufts indistinct.

FEMALE. Unknown.

Genitalia ơ (Figs 40-43). Capsule about $320 \mu \mathrm{m}$ long. Uncus comprising two very large, distally rounded lobes. Tegumen band-shaped, slightly spined distally. Gnathos with two very slender and long caudal processes and pair of anterior processes that are $3 \times$ broader and about one-half length of anterior processes; central plate very slender; lateral arms short and narrow. Valva 190-196 $\mu \mathrm{m}$ long, bulged medially and constricted to a pointed apical process caudally, with long plumose scales in apical half. Transtilla with sublaterally directed processes and transverse bar which is not fused in the middle. Ventral plate of vinculum with deep, semicircular anterior excavation and long, distally truncate lateral lobes. Aedeagus 215-226 $\mu \mathrm{m}$ long, slender, with tiny, pointed apical processes on both sides of the tube, and with a few fine, spine-like cornuti in the apical part. Juxta membranous, lobate, hardly visible.

\section{BIOLOGY. Adults collected in late January.}

DIAGNOSIS. Belongs to the same species-group (see Remarks) as two other Neotropical species: plumosetaeella Newton \& Wilkinson and barbata Puplesis \& Robinson. Externally this species is easily distinguished from the fasciated plumosetaeella by the dark forewing; it is externally similar to barbata but differs in the absence of brownish androconial scales at the apex of forewing and in the absence of long thickened brown androconial scales on the dorsal margin of the hindwing. In the male genitalia austroamericana is easily distinguished from both related species by the long lobes of the vinculum, the huge, deeply lobate uncus, and long, almost straight apical processes of the valva.

DISTRIBUTION. Ecuador; Amazon premontane rainforest, at altitudes of about $500 \mathrm{~m}$.

CONDITION OF TYPE MATERIAL. The holotype is well preserved.

Material eXAmined. Holotype $\sigma^{\top}$, Ecuador: Napo Region, SE of Tena, near Rio Napo, Jatun Sacha, Amazon rainforest, $500 \mathrm{~m}, 26-31 . i .2000$ (Puplesis \& Hill), genitalia slide no. 29613 (BMNH).
REMARKS. This species represents a very distinctive member of a still unnamed species-group obviously comprising also plumosetaeella Newton \& Wilkinson and barbata Puplesis \& Robinson; on some similarities in forewing pattern and genitalia it is also easy to assume that austroamericana is more related to barbata Puplesis \& Robinson; they may represent allopatric sister-species.

\section{FOMORIA Beirne}

\section{Fomoria repanda Puplesis \& Diškus sp. n.}

(Figs 9, 44-52)

MALE (Fig. 9). Forewing length: 1.6-1.9 mm. Wingspan: $3.7-4.4 \mathrm{~mm}$. Head: palpi cream to ochreous cream; frontal tuft ochreous orange; collar indistinct, comprising pale ochreous piliform scales; eyecaps cream with or without some pale brownish scales; antenna brownish to brown or ochreous brown on upperside, cream on underside, comprising of 24-28 segments. Thorax and tegulae ochreous cream with many brownish, brown or dark brown scales; these brown scales may be weakly developed and/or easily lost. Cream to brownish cream background of forewing irrorated with brown and dark brown scales; these dark scales more densely distributed on base of wing, close to costa and especially distinctive and dark behind the fascia, i.e., in apical part of forewing. Fascia medianpostmedial, broad and oblique, formed by fuscous-brown scales. Cilia ochreous cream. Underside of forewing yellowish brown. Hindwing and cilia cream. No androconia on hindwing or forewing. Legs cream with or without some dark brown shading. Abdomen yellowish brown on upperside, paler on underside.

\section{FEMALE. Unknown.}

Genitalia $\sigma^{*}$ (Figs 44-52). Capsule 330-342 $\mu \mathrm{m}$ long. Pseuduncus distinctly bilobed; the lobes very large, irregularly triangular. Uncus with distally rounded median lobe (see Remarks). Gnathos with relatively short caudal element and long slender lateral arms. Valva 100-109 $\mu \mathrm{m}$ long, divided into slender, distally rounded and setose lobe, and slender and distally pointed dorsal lobe. Transtilla with very extended lateral arms and with an angular plate (transverse bar); plate of transtilla weakly sclerotized. Vinculum very long, without anterior (distal) excavation or lobes. Juxta apparently absent. Aedeagus very large, about $575 \mu \mathrm{m}$ long, with a wide band of broad, triangular and lobe-like cornuti, and with about seven very large horn-like cornuti in apical one-quarter; three orfour of these horn-like cornuti straight, remainder with curved bases. Aedeagus of holotype (Fig. 45) with inverted vesica, and not all cornuti preserved and visible; see paratype (Fig. 52). 
BIOLOGY. Adults fly in January.

DiAGNOSIS. This distinctive Amazon rainforest species forms a natural group with a few other Neotropical Fomoria: molybditis (Zeller) [Colombia], diskusi Puplesis \& Robinson [Belize], and unnamed species 29122 [Belize] (see Puplesis \& Robinson, 2000). Externally repanda differs from all these species in the dark fascia of the forewing. The male genitalia exhibit some similarities to molybditis and species 29122 in the presence of numerous cornuti in the aedeagus. However, repanda clearly differs from molybditis in the deeply divided valva without a spinelike process and in the broad median lobe (element) of the uncus; from species 29122 it differs in the very long aedeagus, slender ventral lobe of the valva, and broad uncus.

Distribution. Lowland Amazon rainforest (Ecuador).

CONDITION OF TYPE MATERIAL. Holotype and paratype well preserved.

MATERIAL EXAMINED. Holotype $\sigma^{\star}$, Ecuador: Napo Region, SE of Coca, near Rio Tiputini, Yasuni National Park, 260 m, 15-25.i.2000 (Puplesis \& Hill), genitalia slide no. 29603 (BMNH). Paratype: $\sigma^{\star}$, data as holotype, genitalia slide no. AD0315 (VPU),

REMARKS. In the genitalia slides of both currently known specimens the median lobe of the uncus is directed anteriorly, but it is uncertain that this is the natural position and not an artefact of preparation. The normal position might well be with the median lobe directed caudally, as is characteristic of other Fomoria.

\section{Fomoria tabulosa Puplesis \& Diškus sp. n.}

(Figs 10, 53-55)

MALE (Fig. 10). Forewing length: $2.6 \mathrm{~mm}$. Wingspan: about $5.6 \mathrm{~mm}$. Head: palpi cream with some brownish shading; frontal tuft pale ochreous; collar inconspicuous, comprised of ochreous cream piliform scales; eyecaps large, yellowish cream; antenna ochreous cream distinctly annulated with brown, comprising of about 35 segments. Thorax, tegulae and forewing uniform: greyish cream background densely irrorated with brown and dark brown scales. Cilia and underside of forewing brownish. Hindwing lanceolate, brownish; its cilia also brownish. No androconia on forewing or hindwing. Legs pale ochreous distally with fuscous shading. Abdomen brown; tufts weakly developed.

FEMALE. Unknown.

Genitalia $\sigma$ (Figs 53-55). Capsule 408-415 $\mu \mathrm{m}$ long. Pseuduncus triangular with a short, slender and distally truncate process. Uncus inverted ' $V$ '-shaped, with short and blunt extension, which in most Fomoria is caudally directed [the extension of the uncus in a ventral direction in the holotype - see Fig. 53 - was probably caused by the process of fixation and mounting in Euparal]. Gnathos with single, slender caudal process and slender, caudally directed lateral arms. Valva $240-253 \mu \mathrm{m}$ long, broad at base, strongly narrowed towards apex, very slender and slightly curved inwardly in apical third. Transtilla with slender transverse bar and short, slender sublateral processes. Juxta (Fig. 54) represented by a pair of lateral, lobe-like, spinose processes behind (dorsal to) ventral lobes of valvae. Ventral plate of vinculum half length of valva, narrowed distally and with small rounded sublateral corners; distal excavation of vinculum plate particularly shallow. Aedeagus $332 \mu \mathrm{m}$ long, with broad inverted ' $U$ '-shaped sclerite; no apical carinae or spinelike cornuti.

BIOLOGY. Adults collected in January.

DiAGNOSIS. Easily distinguished from other Fomoria and all other nepticulids by the inverted ' $U$ '-shaped sclerite in the aedeagus.

DisTRIBUTION. Lowland Amazon rainforest (Ecuador).

CONDITION OF TYPE MATERIAL. The holotype is in good condition.

Material eXamined. Holotype $\sigma^{\star}$, Ecuador: Napo Region, SE of Coca, near Rio Tiputini, Yasuni National Park, 260 m, 15-25.i.2000 (Puplesis \& Hill), genitalia slide no. 29625 (BMNH).

\section{ACALYPTRIS Meyrick}

\section{Acalyptris ecuadoriana Puplesis \& Diškus sp. $n$.}

(Figs 11, 56-58)

MALE (Fig. 11). Forewing length: $2.5 \mathrm{~mm}$. Wingspan: $5.4-5.5 \mathrm{~mm}$. Head: palpi cream; frontal tuft ochreous; collar indistinct, consisting of ochreous cream piliform scales; eyecaps large, cream, with some brownish scales; antenna on upperside broadly annulated with brown to almost cream, cream on underside, comprising of about 28 segments. Thorax, tegulae and forewing before the fascia golden cream with some brownish scales close to forewing costa. Fascia postmedial, oblique, formed by fuscous brown scales; area behind fascia brown-grey with some fuscous-brown tipped scales. Cilia cream. Some long, thickened, dark brown scales extending over hindwing from dorsal margin of forewing. Underside of forewing brownish cream except margins which are brown. Hindwing lanceolate, neatly covered with small brownish (probably androconial) scales (on upperside only); cilia of hindwing brownish or greyish. Legs ochreous cream. 
Abdomen dark brown to yellowish brown with some dark brown scales; on upperside - brownish to yellowish.

\section{FEMALE. Unknown.}

GENITALIA $\sigma^{*}$ (Figs 56-58). Capsule $280 \mu \mathrm{m}$ long. Pseuduncus triangular and neatly papillated distally. Uncus paired, X-shaped, broadened anteriorly. Gnathos (Fig. 57) with slender, bar-like central plate, and very elaborate, unusual lateral arms, their ventrally sclerotized margins resembling distinctly pointed caudal processes; ventral arms of gnathos with inwardly directed dorsal lobes; real caudal process(es) absent. Tegumen not forming lateral rod-like sclerites beneath valvae, along capsule as in many other Neotropical Acalyptris. Valva 168-173 $\mu \mathrm{m}$ long, broad in basal two-thirds and very slender, inwardly curved in apical third. Transtilla with narrow, medially very constricted (or not fused) transverse bar and outwardly curved sublateral processes one-half length of transtilla. Juxta a sclerotized transverse bar behind valval bases, slightly varying in shape. Ventral plate of vinculum with widely rounded lateral lobes and very shallow anterior excavation. Aedeagus $244 \mu \mathrm{m}$ long, sclerotized and distinctly constricted at base, and with three very long horn-like sclerites in apical half; one of them with a strongly sclerotized basal extension.

\section{BIOLOGY. Adults collected in January.}

DiAGNOSIS. Together with the Amazonian onorei and the Central American latipennata Puplesis \& Robinson and dividua Puplesis \& Robinson this species forms a distinctive species group. Externally ecuadoriana clearly differs from onorei in the welldeveloped forewing fascia, the absence of androconial patches on the hindwing and by the lanceolate hindwing shape; in onorei the hindwings are distinctly broadened. From latipennata and dividua it differs in the presence of long piliform scales on the dorsal margin of the forewing and by the background colour of the forewing - latipennata is paler, and dividua darker. In the male genitalia this species differs from all related ones in the absence of inner, spine-like valval processes, a distinctly X-shaped uncus with broadened anterior components, distally excavated vinculum, very broad valva in basal two-thirds, and the specialized shape of the gnathos.

Distribution. Premontane Amazon rainforest (Ecuador).

CONDITION OF TYPE MATERIAL. The type series is well-preserved.

MATERIAL EXAmined. Holotype $\sigma^{\star}$, Ecuador: Napo Region, near Rio Napo, Jatun Sacha, premontane rainforest, 400-500 m, 26-31.i.2000 (Puplesis \& Hill), genitalia slide no. 29624 (BMNH). Paratypes: 10 data as holotype, genitalia slide no. AD0325 (VPU); $10^{*}$, data as holotype but Misahualli, 22-31.i.2001 (Puplesis \& Hill), genitalia slide no. AD0349 (VPU).

\section{Acalyptris onorei Puplesis \& Diškus sp. $\mathbf{n}$.}

(Figs 1, 12, 13, 59-64)

MALE (Figs 1, 12, 13). Forewing length: 2.0-2.2 $\mathrm{mm}$. Wingspan: $4.5-4.9 \mathrm{~mm}$. Head: palpi cream; frontal tuft ochreous orange; collar indistinct, comprised of ochreous cream piliform scales; eyecaps cream; antenna cream, annulated with brownish to fuscous brown on upperside, comprising of 26-28 segments. Thorax and tegulae irrorated with numerous brownish to brown scales. Forewing broad with some bluish and green reflection; in basal three-fifths, cream to greycream background indistinctly, more or less smoothly irrorated with brownish scales, apical two-fifths distinctly irrorated with larger, brown to fuscous brown scales; a clear fascia undeveloped, however, numerous fuscous brown scales distributed just behind middle of forewing resemble an irregular, oblique postmedial fascia. Cilia greyish cream. Underside of forewing dark brown with very long, median band of cream androconial scales along width of wing. Forewing venation (Fig. 1) typical for Acalyptris, however R4 and R5 preserved as two separate veins in contrast to the usual Acalyptris venation where these veins are fused. Hindwing (Fig. 13) unusually broad, on upperside with large, elongated patch of neatly arranged cream scales close to hind margin and base; covered with brown scales, very densely deposited just before apex; apex brownish; with single frenulum and, close to base, a dark brown hair pencil comprising many very long, thickened chaetae-like scales; behind hair pencil with many cream, elongated lamellar scales arising from anterior margin of wing. Cilia of hindwing cream, overlapped by long, thickened, brownish scales from posterior margin near apex. Underside of hindwing brownish to brown; sometimes with a paler zone along main vein. Legs pale ochreous or ochreous cream. Abdomen brown with broad dark bands along upperside, underside yellowish brown or brownish.

FEMALE. Unknown.

Genitalia ơ (Figs 59-64). Capsule $295 \mu \mathrm{m}$ long. Pseuduncus with two small triangular lobes apically; excavation between apical lobes as deep/broad as the length/width of each lobe. Uncus (Fig. 62) paired, comprising lateral, strongly sclerotized plates which are widened at distal end and outwardly curved at bases. Gnathos (Fig. 63) paired, comprising two lateral, strongly sclerotized, broad, V-shaped sclerites; no central plate or any transverse bar connecting lateral parts of gnathos. Tegumen not forming lateral rod-like sclerites beneath valvae, along capsule as in many other Neotropical Acalyptris. Valva 175-181 $\mu \mathrm{m}$ long, 
with large, horn-like apical process and similar medial one. A pair of small rounded sclerotizations visible on diaphragma between medial process of valva and transtilla bar; homology of these sclerites unknown. Transtilla with narrow, long, bridge-like transverse bar, and outwardly curved sublateral processes onethird length of bar. Juxta apparently absent. Vinculum large, ventral plate trapezoidal, gradually narrowed towards anterior (distal) end, without lateral lobes and without anterior excavation. Aedeagus about $255 \mu \mathrm{m}$ long, strongly narrowed in basal third, and with three large, horn-like sclerites apically.

BIOLOGY. Adults collected in January.

DiAgnosis. Together with the Amazonian ecuadoriana and two Central American species, latipennata Puplesis \& Robinson and dividua Puplesis \& Robinson, onorei forms a distinctive species group. Externally it differs from these related species in the distinctly broadened hindwing with androconial patches, and weakly developed (or undeveloped) forewing fascia. In the male genitalia onorei differs from all related species by the unique gnathos comprised of two lateral sclerites without a transverse bar.

Distribution. Lowland Amazon rainforest (Ecuador).

CONDITION OF TYPE MATERIAL. The holotype is well preserved; the paratype has a slightly rubbed head and wings.

MATERIAL EXAMINED. Holotype $\sigma^{\star}$, Ecuador: Napo Region, SE of Coca, near Rio Tiputini, Yasuni National Park, 260 m, 15-25.i.2000 (Puplesis \& Hill), genitalia slide no. 29623 (BMNH). Paratype ơ : data as holotype, genitalia slide no. AD0324 (VPU), forewing venation slide no. AD0351 (VPU).

REMARKS. This remarkable species is named in honour of Dr. Giovanni Onore (Departamento de Biologia, Pontificia Universidad Católica del Ecuador, Quito, Ecuador) who helped to organize the first collecting trip to Ecuador specifically targeted at Amazon rainforest Nepticuloidea.

Another species, closely related to onorei, was found by Puplesis \& Hill (2001) in premontane tropical rainforest (Misahualli, $17 \mathrm{~km} \mathrm{SE}$ of Tena). The specimen will not be described until further material becomes available; it is deposited at VPU (genitalia slide no. AD0352).

\section{Acalyptris basihastatus Puplesis \& Diškus sp. $n$.}

(Figs 14, 65-67, 71)

MALE (Fig. 14). Forewing length 1.9-2.1 mm. Wingspan: 4.3-4.6 mm. Head: palpi cream; frontal tuft ochreous to pale orange-ochreous; collar indistinct, comprised of cream piliform scales; eyecaps cream; antenna brownish, comprising of about 33-35 segments. Thorax and tegulae densely irrorated with brown (or dark brown) scales. Golden cream background of forewing (except costal area) irrorated with small, indistinct pale brownish scales; the narrow area along costa densely covered with dark brown scales; apical part of forewing irrorated with dark brown or fuscous-tipped scales; some dark scales overlapping on cilia. Cilia cream. Underside of forewing dark brown. Hindwing lanceolate, brownish or greyish; cilia greyish. No androconial patches on hindwing or forewing. Legs cream with golden reflection. Abdomen dark brown on upperside and yellowish brown on underside, with paired abdominal tuft of long piliform scales.

\section{FEMALE. Unknown.}

Genitalia ơ (Figs 65-67, 71). Capsule 312-320 $\mu \mathrm{m}$ long. Tegumen extended into distally bilobed pseuduncus; each lobe rounded and papillated. Uncus in shape of inverted $\mathrm{Y}$; the caudal process slender and short. Gnathos with large caudal process, somewhat slender lateral arms, and subangular central plate. Tegumen forming lateral rod-like sclerites beneath valvae, along capsule. Valva (Fig. 71) 205-218 $\mu \mathrm{m}$ long, with large, pointed, subcaudally directed basal process, bulged inner lobe and gradually constricted apical half. Transtilla with slender and long transverse bar and similarly slender sublateral processes one-half length of bar. Juxta indistinct or apparently absent. Ventral plate of vinculum broad and short, with very broad, triangular, distally rounded lateral lobes. Aedeagus 439-448 $\mu \mathrm{m}$ long (including distal carina); tube equally broad, apically with five large, mostly asymmetrical carinae and large, elongated, semitriangular sclerotization near bases of lowest (lateral) carinae; in undissected genitalia, this elongated platelike sclerotization probably attaches to caudal margin of vinculum. Vesica with some very small triangular cornuti close to the elongated, plate-like sclerotization. Cathrema very sclerotized, relatively very long, almost as long as any carinae.

\section{BIOLOGY. Adults collected in late January.}

DiaGNOSIS. This species is distinguished from all currently known Neotropical Acalyptris by the large, straight and pointed, distinctly basal process of the valva. Externally it might be confused with other Acalyptris with irrorated forewings, particularly with the central american martinheringi and the related, Amazonian pseudohastatus or articulosus. In martinheringi the somewhat similar basal processes are slightly curved or bifid, and are associated with the juxta, not the valva; the pseuduncus is distally rounded, and the valva slender. In pseudohastatus the valval 
process is attached for its entire length to the inner lobe of the valva and is sinuous, not straight; the pseuduncus is truncated, not bilobed; the aedeagal carinae are very long. In articulosus, in contrast to basihastatus, the basal lobe of the valva is articulated.

DISTRIBUTION. Amazon premontane rainforest (Ecuador), at altitudes of about $500 \mathrm{~m}$.

CONDITION OF TYPE MATERIAL. The holotype and four paratypes are in good or satisfactory condition, with spread wings, and are little worn. The best preserved scaling of forewing and head is undoubtedly in paratype AD0316.

MATERIAL EXAmINED. Holotype $\sigma^{\top}$, Ecuador: Napo Region, near Rio Napo, Jatun Sacha, premontane rainforest, 400-500 m, 26-31.i.2000 (Puplesis \& Hill), genitalia slide no. 29605 (BMNH). Paratypes: $3 \sigma^{\circ}$, data as holotype, genitalia slide nos 29606 (BMNH), AD0316(VPU), AD0317 (VPU); $10^{*}$, data as holotype but Misahualli, 22-31.i.2001 (Puplesis \& Hill), genitalia slide no. AD0350 (VPU).

\section{Acalyptris pseudohastatus Puplesis \& Diškus sp. n.}

(Figs 15, 68-70, 72)

MALE(Fig. 15). Forewing length: 2.1-2.2 mm. Wingspan: $4.7-4.9 \mathrm{~mm}$. Head: palpi cream; frontal tuft ochreous orange to pale ochreous; collar indistinct, comprised of cream piliform scales; eyecaps cream; antenna brown to brownish, comprising of about 36-38 segments. Thorax and tegulae densely irrorated with brown (or dark brown) scales. Greyish cream or golden cream background of forewing irrorated with brownish, brown and dark brown scales; dark brown-tipped scales particularly abundant in apical half of forewing; some dark scales overlapping on forewing cilia; a narrow area along costa densely covered with dark brown scales. Cilia greyish. Underside of forewing brown to dark brown. Hindwing lanceolate, grey or brownish; cilia grey. No androconial patches on hindwing or forewing. Legs brownish cream with dark brown shading (particularly on forelegs). Abdomen dark brown on upperside and yellowish brown on underside, with paired abdominal tuft of long piliform scales.

FEMALE. Unknown.

GENITALIA ơ (Figs 68-70, 72). Capsule 340-354 $\mu \mathrm{m}$ long. Tegumen extended into trapezoidal, distally truncate pseuduncus. Uncus in shape of invertedY; the caudal process slender and short. Gnathos with large caudal process, slightly slender lateral arms, and with small central plate. Tegumen forming lateral rod-like sclerites beneath valvae, along capsule. Valva (Fig. 72) 240-249 $\mu \mathrm{m}$ long, with large, pointed, caudally directed median process, bulged inner lobe and gradually constricted apical half. Transtilla with slender and long transverse bar and very slender sublateral processes half length of bar. Juxta indistinct or apparently absent. Ventral plate of vinculum broad and very short, with triangular, short, distally almost pointed lateral lobes. Aedeagus 350-362 $\mu \mathrm{m}$ long (including distal carina); tube equally broad, apically with five very large carinae and some very small triangular cornuti on vesica. Cathrema well sclerotized and half as long as any apical carinae.

\section{BIOLOGY. Adults collected in late January.}

DIAGNOSIS. This species is very easily distinguished from other Neotropical Acalyptris by the combination of the very characteristic median process of the valva with the truncate pseuduncus and five very long aedaegal carinae. Relationships are to other Amazonian Acalyptris, notably basihastatus; however, in pseudohastatus the valval process is attached for its entire length to the inner lobe of the valva and is sinuous, not straight; the pseuduncus is truncate (not bilobed), the carinae of the aedeagus are very long and very slender distally.

Externally it could be easily confused with other Acalyptris with a similarly irrorated forewing, particularly the central american martinheringi and Amazonian basihastatus and articulosus.

DISTRIBUTION. Amazon premontane rainforest (Ecuador), at altitudes of about $500 \mathrm{~m}$.

CONDITION OF TYPE MATERIAL. The holotype and one paratype (no. AD0319 VPU) are in good condition, while the two remaining paratypes are more worn (no. 29608 BMNH and no. AD0316 VPU).

MATERIAl EXAMINED. Holotype $\sigma^{*}$, Ecuador: Napo Region, near Rio Napo, Jatun Sacha, premontane rainforest, $500 \mathrm{~m}, 26-31 . i .2000$ (Puplesis \& Hill), genitalia slide no. 29607 (BMNH). Paratypes, $30^{\circ}$, data as holotype, genitalia slides no. 29608 (BMNH), no. AD0318 (VPU), no. AD0319 (VPU).

\section{Acalyptris articulosus Puplesis \& Diškus sp. n.}

(Figs 16, 73-75)

MALE (Fig. 16). Forewing length: $1.8-2.0 \mathrm{~mm}$. Wingspan: 4.3-4.5 mm. Head: palpi cream; frontal tuft dark orange or dull orange; collar comprising orange-cream piliform scales; eyecaps cream; antenna brownish to brownish cream, comprising of about 34-36 segments. Thorax and tegulae irrorated with brown (or dark brown) scales. Cream background of forewing irregularly irrorated with indistinct, small, pale brown scales, densest in basal half of wing, and with brown to fuscous brown scales predominating in apical half of forewing; no fascia or distinct spots, but a few dark fuscous scales together may form a patch, however, this patch not obviously developed on other wing of 
same specimen; some dark scales overlapping on forewing cilia. Cilia brownish cream. Yellowish cream background of underside of forewing densely covered with small elongated dark brown scales. Hindwing generally slender, slightly broadened anteriorly in basal half, uniformly covered either with grey-cream or brownish grey scales; cilia of hindwing greyish. No androconial patches on hindwing or forewing. Legs brownish cream to cream with or without fuscous shading distally. Abdomen brown on upperside and yellowish brown on underside, with paired abdominal tuft of long piliform scales.

FEMALE. Unknown.

Genitalia $\sigma^{*}$ (Figs 73-75). Capsule 270-276 $\mu \mathrm{m}$ long. Tegumen caudally extended into a gradually tapered pseuduncus, with two slender and short distal lobes. Uncus inverted ' $\mathrm{Y}$ '-shaped, with a short, slender, apically thickened and slightly broadened caudal process. Gnathos with short, strongly sclerotized lateral arms; central plate relatively large, laterocaudally very strongly sclerotized, anteriorly with more or less membranous, triangular extension. Valva 216-229 $\mu \mathrm{m}$ long, slender for entire length, with caudally directed basal lobe; lobe divided caudally into two unequally developed and unequally sclerotized processes. Transtilla with long transverse bar and short, very slender sublateral process. Without the lateral rod-like sclerites beneath valvae and along capsule, characteristic of very many Acalyptris, particularly Neotropical species. Ventral plate of vinculum very short, gradually constricted distally, with two very small, rounded lateral lobes with very shallow excavation between them. Aedeagus 287-317 $\mu \mathrm{m}$ long, very broad (114-126 $\mu \mathrm{m})$, with a pair of curved, horn-like lateral carinae joined by a common transverse bar, five or four (minimum three) large, horn-like cornuti, and numerous tiny, spine-like triangular cornuti; cathrema strongly sclerotized, short and very broad.

BIOLOGY. Adults collected in late January.

DiAGNOSIS. This species is easily distinguished from other Acalyptris by the basal lobe of the valva which is clearly and deeply divided into two unequally developed processes, and by the combination of a bilobed pseuduncus with a broadened central gnathos plate, and tiny vinculum. Externally this species could be easily confused with some other Acalyptris possessing similarly irrorated forewings, particularly with the Central American martinheringi, and the Amazonian basihastatus and pseudohastatus (see above).

Distribution. Amazon premontane rainforest (Ecuador), at altitudes of about $500 \mathrm{~m}$.

CONDITION OF TYPE MATERIAL. The holotype is in fair condition, however the pattern of the forewings is not very distinct; the specimen with the best preserved scaling and the most distinct forewing pattern is paratype no. $29609 \mathrm{BMNH}$; however, the head of this specimen is detached and glued to a separate minuten pin. The remaining paratype, no. AD0320 VPU is in fair condition, but the hindwings are detached and stored in a small gelatine capsule beneath the specimen.

MATERIAL EXAMINED. Holotype $\sigma^{*}$, Ecuador: Napo Region, near Rio Napo, Jatun Sacha, premontane rainforest, 500 m, 26-31.i.2000 (Puplesis \& Hill), genitalia slide no. 29610 (BMNH). Paratypes: $20^{\circ}$, data as holotype, genitalia slides no. 29609 (BMNH), no. AD0320 (VPU).

\section{Acalyptris rotundus Puplesis \& Diškus sp. $\mathbf{n}$.}

(Figs 17, 76-78)

MALE (Fig. 17). Forewing length: about $1.9 \mathrm{~mm}$. Wingspan: about 4.3-4.4 mm. Head: palpi cream; frontal tuft ochreous orange or orange; collar inconspicuous, comprised of orange-cream piliform scales; eyecaps cream; antenna mostly brownish cream or cream with some dark brown shading, comprising of about 33-34 segments. Thorax and tegulae pale creamy brown, indistinctly irrorated with brownish scales. Brownish cream background of forewing irrorated with brownish and brown scales before middle, and with predominantly larger fuscous scales in apical half or two-fifths; forewing pattern tending to be irregular, but with median, broad, ill-defined fascia formed by whitish cream scales; a few whitish scales also forming an indistinct, small, more or less rounded apical spot that is unequally developed on both wings of the same specimen. Cilia distinctly grey, except distal area. Underside of forewing brown. Hindwing lanceolate, greyish or brownish; its cilia brownish. No androconial patches on hindwing or forewing. Legs dark cream. Abdomen with a distinct cream abdominal tuft of long piliform scales, dark brown on upperside and yellowish brown on underside.

\section{FEMALE. Unknown.}

Genitalia ơ (Figs 76-78). Capsule 204-224 $\mu \mathrm{m}$ long, distinctly rounded. Pseuduncus distinctly rounded, strongly sclerotized and papillated. Uncus broad, inverted ' $\mathrm{Y}$ '-shaped with two very strongly sclerotized, lateral, slightly anteriorly curved and distally pointed processes, almost as long as caudal process; caudal process well-sclerotized, slender. Gnathos with large caudal process, broad but short lateral arms and relatively large central plate excavated from anterior margin. Valva about 120-125 $\mu \mathrm{m}$ long, generally narrow, slightly broadened towards base, with many papillae on inner margin. Both valvae joined basally by ventral transverse bar which forms a central triangular sclerotization. Transtilla with very narrow transverse bar and tiny, very slender sublateral proc- 
esses. Well-sclerotized lateral rod-like sclerites beneath valvae, along capsule, as is characteristic of very many Acalyptris species, particularly Neotropical ones. Ventral plate of vinculum extremely small, band-like, distally truncate or rounded, without any lateral lobes and distal excavation. Aedeagus about $100 \mu \mathrm{m}$ long, broad and short, with two lateral, long, very slender and pointed carinae, and very many small, fine cornuti.

BIOLOGY. Adults collected in late January.

DIAGNOSIS. This species is very easily distinguished from other Acalyptris by the combination of the very characteristic, three-processed uncus and the distinctly rounded capsule, and the broad, rounded pseuduncus and broad aedeagus with two very slender lateral carinae. While the unusual cream forewing fascia of this species may be thought of as distinctive, the character is of limited value since it is not well-defined and even slight abrasion may render it very hard to recognise.

DistribUtion. Amazon premontane rainforest (Ecuador), at altitudes of about $500 \mathrm{~m}$.

CONDITION OF TYPE MATERIAL. The holotype is in quite good condition, with well-preserved scaling; the wings are not spread but the hindwing is easily visible.

MATERIAl EXAMINED. Holotype $\sigma^{\star}$, Ecuador: Napo Region, near Rio Napo, Jatun Sacha, premontane rainforest, $500 \mathrm{~m}, 26-31 . i .2000$ (Puplesis \& Hill), genitalia slide no. 29611 (BMNH).

\section{Acalyptris amazonius Puplesis \& Diškus sp. n.}

(Figs 18, 79-82, 93)

MALE (Fig. 18). Forewing length: $1.5 \mathrm{~mm}$. Wingspan: 3.4-3.5 mm. Head: palpi yellowish cream; frontal tuft orange-ochreous, distally ochreous brown; collar indistinct, comprised of pale ochreous or ochreous cream piliform scales; eyecaps yellowish cream; antenna dark brown on upperside and yellowish cream on underside, comprising of 24-26 segments. Thorax and tegulae dark brown, unicolorous. Forewing generally dark, basal three-fifths brown, then with an indistinct, oblique, fascia-like, paler, brownish-cream area; apical area of forewing densely irrorated with fuscous brown scales. Cilia pale brown. Underside of forewing dark brown or brown. Hindwing and cilia grey-brown. No androconia on hindwing or forewing. Legs brownish cream with abundant brown to fuscous brown shading laterally and distally. Abdomen fuscous brown, very reflective on upperside and with brown gloss on underside; pair of anal tufts distinct, composed of long piliform scales.

FEMALE (see Remarks). Forewing length: 1.6-1.7 $\mathrm{mm}$. Wingspan: $3.7 \mathrm{~mm}$. Head: palpi whitish; frontal tuft whitish cream; collar sometimes indistinct, comprised of cream piliform scales; eyecaps cream, with some brownish scales; antenna brown on upperside and brownish on underside, comprising of about $27-$ 28 segments. Thorax and tegulae dark brown, unicolorous. Forewing generally dark, basal threefifths brown, apically irrorated with fuscous brown scales; pale area before the apical region, characteristic in the male, absent. Cilia brown. Underside of forewing brown. Hindwing and cilia grey-brown. Legs brownish cream with some brown to fuscous brown shading. Abdomen fuscous on upperside, with reddish and purple reflection and pale silvery on underside.

GENITALIA $\sigma^{*}$ (Figs 79-82). Capsule 240-250 $\mu \mathrm{m}$ long. Tegumen extended into broad, distally widelyrounded and heavily papillated pseuduncus; anteriorly with unusual trapezoidal extension. Uncus (Fig. 81) with lateral band-like components and caudal element directed ventrally; the last very strongly sclerotized and resembling a crown. Gnathos with small pointed caudal process, small oval central plate and well developed lateral lobes wider than the caudal element. Valva 134-139 $\mu \mathrm{m}$ long, equally narrow for entire length except apex which is visibly constricted and very strongly papillated; basally valva strongly sclerotized. Transtilla with slender transverse bar and sublateral processes one-half length of bar. Juxta apparently absent. Ventral plate of vinculum half length of valva, slightly and gradually constricted distally, and with shallow anterior excavation; lateral lobes weakly developed, broadly triangular. Lateral rod-like sclerites (usually very characteristic for Neotropical Acalyptris) distinct and sclerotized only distally while at bases not demarcated from tegumen. Aedeagus about $263 \mu \mathrm{m}$ long, with pair of slender lateral carinae, long and well-sclerotized cathrema, four slender and long spinelike cornuti, and a few very tiny, indistinct ones.

GENITALIA + (Fig. 93) (see Remarks). Total length about 702-708 $\mu \mathrm{m}$. Abdominal tip broadly rounded. Anal papillae undeveloped, but with a distinct, sclerotized plate connected with bases of apophyses anteriores. Both anterior and posterior apophyses very slender, but anterior apophyses one-third to one-quarter longer $(125-138 \mu \mathrm{m})$. Vestibulum with large Y-shaped sclerite. Corpus bursae large, elongate-oval with a distinct, band-like signum on each side, with tiny pectinations around the signa. Accessory sac undeveloped; ductus spermathecae with 8-9 compactly arranged convolutions.

\section{BIOLOGY. Adults collected in January.}

DiAgNosis. Among Neotropical Acalyptris this species resembles externally only the dark Central American hispidus Puplesis \& Robinson, novenarius Puplesis \& Robinson and platygnathos Puplesis \& Robinson; however, it is easily distinguished by the genitalia.

In the male genitalia amazonius differs very strongly 
by the crown-shaped uncus and by the apically slightly constricted but heavily papillated valva.

Distribution. Lowland Amazon rainforest (Ecuador).

CONDITION OF TYPE MATERIAL. The holotype is well preserved.

MATERIAL EXAmINED. Holotype $\sigma^{\star}$, Ecuador: Napo Region, SE of Coca, near Rio Tiputini, Yasuni National Park, 260 m, 15-25.i.2000 (Puplesis \& Hill), genitalia slide no. 29612 (BMNH). Excluded from paratype status: 19 , data as holotype, genitalia slide no. AD0330 (VPU).

REMARKS. A single female has been associated with the holotype since it has very similar dark forewings with fuscous apical irroration; it is similarly small and was collected at the same time in the same locality. However, there are some points of difference which make us preclude this specimen from paratype status: 1) the palpi are whitish, not yellowish cream as in the male; 2 ) the head is slightly rubbed and comparison with the holotype is difficult, but the tuft still present is quite whitish (not orange-ochreous as in the male); 3 ) there is no pale postmedial area developed on the forewing as in the male; 4) the abdomen is silvery on the underside, not brown.

\section{Acalyptris insolentis Puplesis \& Diškus sp. n.}

(Figs 19, 83-88)

MALE (Fig. 19). Forewing length: 1.7-2.0 mm. Wingspan: $3.8-4.5 \mathrm{~mm}$. Head: palpi cream; frontal tuft orange or pale ochreous; collar indistinct, comprised of cream piliform scales; eyecaps cream to whitish; antenna brownish, comprising of about 24 segments. Thorax and tegulae yellowish cream. Forewing with slightly variable but distinct pattern; basal area before fascia, except large costal area, covered with small, pale brownish scales; costal area distinctly paler, yellowish cream, as tegulae; fascia slightly postmedial, distinctly oblique and broadening at tornus, formed by fuscous brown and brown scales; area beyond the fascia yellowish cream; apex of forewing with yellowish cream background but irrorated with brown and fuscous scales; some fuscous scales overlapping onto cilia. Cilia cream only at distal end of forewing, otherwise grey or greyish. Underside of forewing brown to ochreous brownish. Hindwing lanceolate, brown or pale brownish depending upon angle of observation; cilia greyish to grey. No androconial patches on hindwing or forewing. Legs ochreous cream. Abdomen brown on upperside, yellowish brown on underside, with a pair of cream abdominal tufts composed of long piliform scales.

FEMALE. Unknown.

Genitalia ${ }^{*}$ (Figs 83-88). Capsule 270-280 $\mu \mathrm{m}$ long. Tegumen extended into short, broadly rounded pseuduncus. Uncus (Fig. 84) with lateral, wellsclerotized, rod-like parts and broadened, lobe-like caudal element. Gnathos (Fig. 85) complex and distinctive; central plate large, with oval anterior extension and broad lobe-like caudal extension homologous with caudal process of other Acalyptris; the last weakly sclerotized, almost membranous, usually inconspicuous even in stained slides; lateral arms of vinculum very broad, almost as broad as long. Tegumen with two distinct, lateral rod-like sclerites along capsule beneath valvae. Valva $176 \mu \mathrm{m}$ long, straight, generally narrow, slightly bulged inwardly before apex and at base; no processes developed. Transtilla with very slender transverse sublateral processes, more than one-half length of transverse bar which may be straight in contrast to Fig. 83. Juxta formed by vinculum posterior margin and attached to ventral side of aedeagus, a small, sclerotized, variable, oval to rounded, triangular or square lobe between bases of valvae. Vinculum very short with unusually long, slender, distally truncate lateral lobes; anterior excavation square and deep. Aedeagus $212-220 \mu \mathrm{m}$ long, with two large paired lateral carinae and large, ventral lobe-like extension attached to vinculum; cornuti either absent, or occasionally represented by an indistinct single spine.

\section{-BIOLOGY. Adults collected in January.}

DiAGNOSIS. Externally this species resembles the Central American hispidus Puplesis \& Robinson, novenarius Puplesis \& Robinson and laxibasis Puplesis \& Robinson; however insolentis differs in the presence of a large, yellowish cream costal area. In the male genitalia the characteristic gnathos with caudal and anterior extensions distinguish this species from all known Acalyptris; the lobate caudal component of the uncus together with the slender lateral lobes of the vinculum are also, in combination, distinguishing characters.

Distribution. Premontane and lowland Amazon rainforest (Ecuador); thus apparently more widespread, at least in the western Amazon basin, than any other species found so far.

CONDITION OF TYPE MATERIAL. The holotype and three paratypes are in good condition but the frontal tuft of the holotype is rubbed; the fourth paratype (AD0323 VPU) has the detached hindwings stored in a small gelatine capsule beneath the specimen.

Material eXAmined. Holotype $\sigma^{\top}$, Ecuador: Napo Region: near Rio Napo, Jatun Sacha, premontane rainforest, $500 \mathrm{~m}, 26-31 . i .2000$ (Puplesis \& Hill), genitalia slide no. 29621 (BMNH). Paratypes: $2 \sigma^{\circ}$, data as holotype, genitalia slides nos 29622 (BMNH) and AD0329 (VPU); $1 \sigma^{\star}$, SE of Coca, near Rio Tiputini, Yasuni National Park, 260 m, 15-25.i.2000 (Puplesis \& Hill), genitalia slide no. AD0323 (VPU). 


\section{REFERENCES}

Bourquin,F. 1962. Microlepidopteros nuevos con sus biologias. Revista de la sociedad Entomologica Argentina, Buenos Aires, 23: 31-46.

Davis, D.R. 1978. New leaf-mining moths of the family Nepticulidae from Florida. The Florida Entomologist, 61 (4): 209-224.

Davis, D.R. 1984. Nepticulidae. In: Heppner, J. B. (ed.) Atlas of Neotropical Lepidoptera. Checklist: part 1. Micropterigoidea Immoidea. Junk, den Haag. xxvii +112 pp.

Davis, D.R. 1985. A re-examination of Enteuch a cyanochlora Meyrick and its subsequent transfer to the Nepticulidae (Lepidoptera: Nepticuloidea). Proceedings of the Entomological Society of Washington, 87: 142-145.

Forbes, W.T.M. \& Leonard, M.D. 1930. A new leaf-miner of cotton in Porto Rico (Nepticula gossypii n. sp.). Journal of the Department of Agriculture, Porto Rico, 14: 149-157.

Meyrick, E. 1915. Descriptions of South American Micro-Lepidoptera. Transactions of the Entomological Society of London, 48(2): 201-256.

Meyrick, E. 1931. Micro-Lepidoptera from South Chile and Argentina. Anales del Museo nacional de Historia Natural, Buenos Aires, 36: $377-415$.

Newton, P.J. \& Wilkinson, C. 1982. A taxonomic revision of the north American species of Stigmella (Lepidoptera: Nepticulidae). Systematic Entomology, 7: 367-463.

Puplesis, R., Diškus, A., Robinson, G.S. \& Onore, G. 2002. A review and checklist of the Neotropical Nepticulidae (Lepidoptera). Bulletin of The Natural History Museum, London (Entomology), 71 (1): 59-76.

Puplesis, R. \& Robinson G.S. 1999. Revision of the Oriental Opostegidae (Lepidoptera) with general comments on phylogeny within the family. Bulletin of The Natural History Museum, London (Entomology), 68 (1): 1-92.

Puplesis, R. \& Robinson G.S. 2000. A review of the Central and South American Nepticulidae (Lepidoptera) with special reference to Belize. Bulletin of the Natural History Museum, London (Entomology), 69 (1): 3-114.

Robinson, G.S. 1976. The preparation of slides of Lepidoptera genitalia with special reference to the Microlepidoptera. Entomologist's Gazette, 27: 127-132.

Wilkinson, C. 1981. A supplement to the genus Ectoedemia Busck (Nepticulidae: Lepidoptera) in North America, dealing with some difficult species and also some new ones. Tijdschrift voor Entomologie, 124 (3): 93-110.

Zeller, P. C. 1877. Exotische Microlepidoptera. II. Horae Societatis Entomologicae Rossicae, 13: 289-493.

\section{INDEX}

Principal references are in bold.

\section{ACALYPTRIS 27}

acuta 21

amazonius 32

andina 23

articulosus $\mathbf{3 0}$

austroamericana $\mathbf{2 5}$

barbata 26

basihastatus 29, 30, 31

cuprata 23

diskusi 27

dividua 28,29

ecuadoriana 27,29

\section{ENTEUCHA 21}

\section{FOMORIA 26}

gilvafascia 21

guajavae $\mathbf{2 2}$

hispidus 32,33

insolentis $\mathbf{3 3}$

latipennata 28,29

laxibasis 33

martinheringi $29,30,31$

molybditis 27

montanotropica $\mathbf{2 3}$

novenarius 32,33

nubimontana $\mathbf{2 4 ,} 25$

onorei $\mathbf{2 8}$

platygnathos 32

plumosetaeella 26

pseudohastatus 30, 31

repanda $\mathbf{2 6}$

rotundus $\mathbf{3 1}$

rubeta $\mathbf{2 4}, 25$

salicis group 23, 24

snaddoni 21

species 2912227

STIGMELLA 23

tabulosa 27 


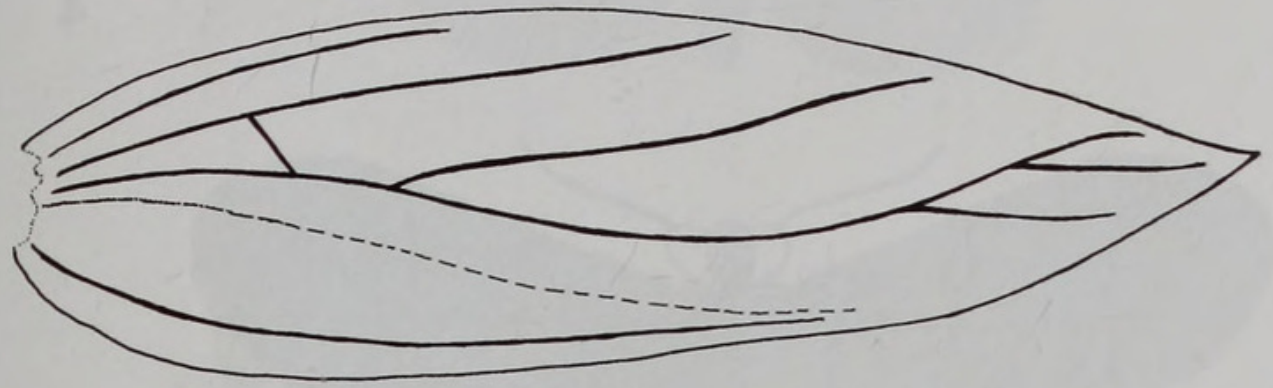

1

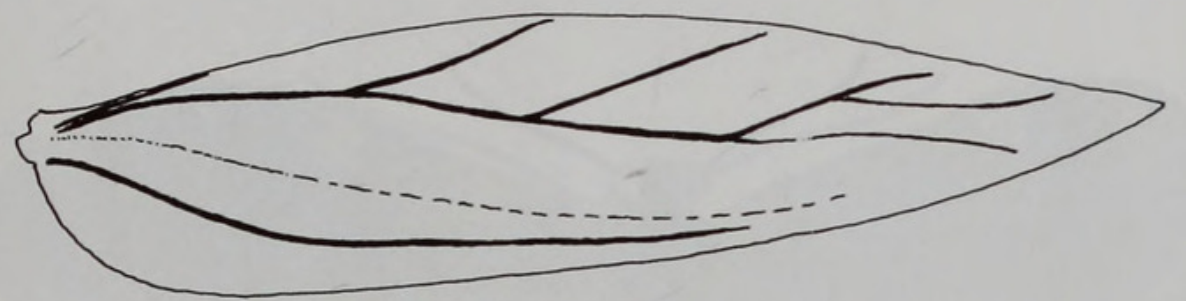

2

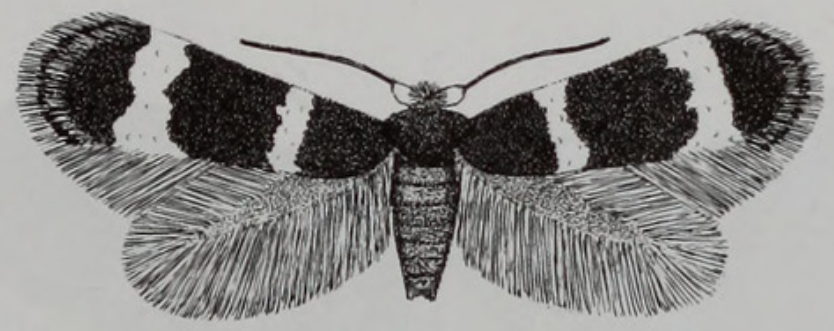

Figs 1-3. Neotropical Nepticulidae. 1, Acalyptris onorei forewing venation; 2, Enteucha guajavae forewing venation; 3 , same, adult moth. 


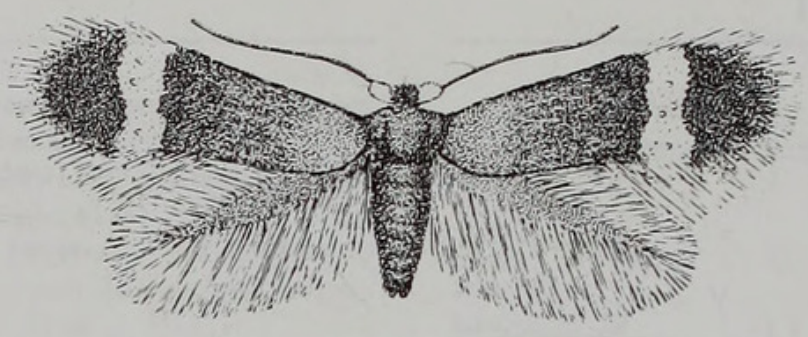

4

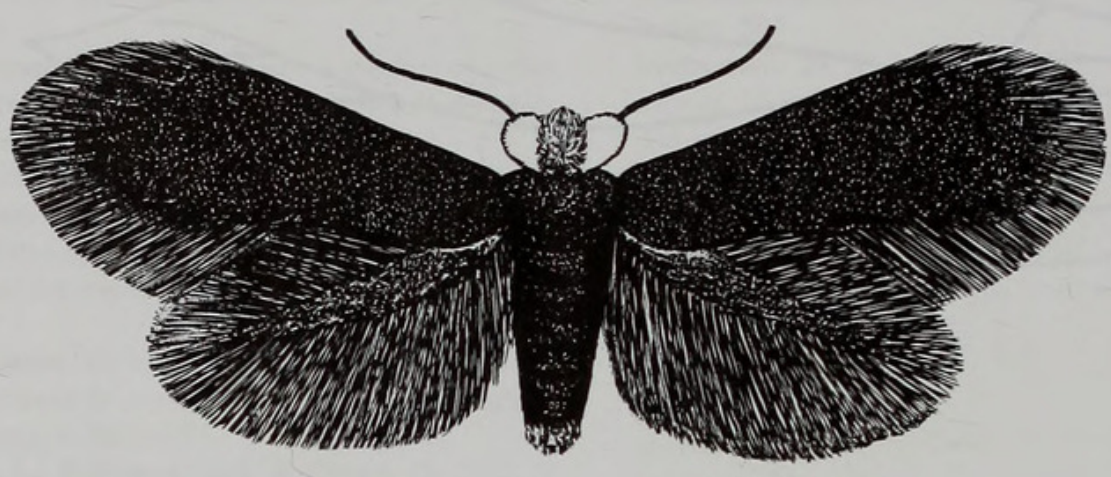

5

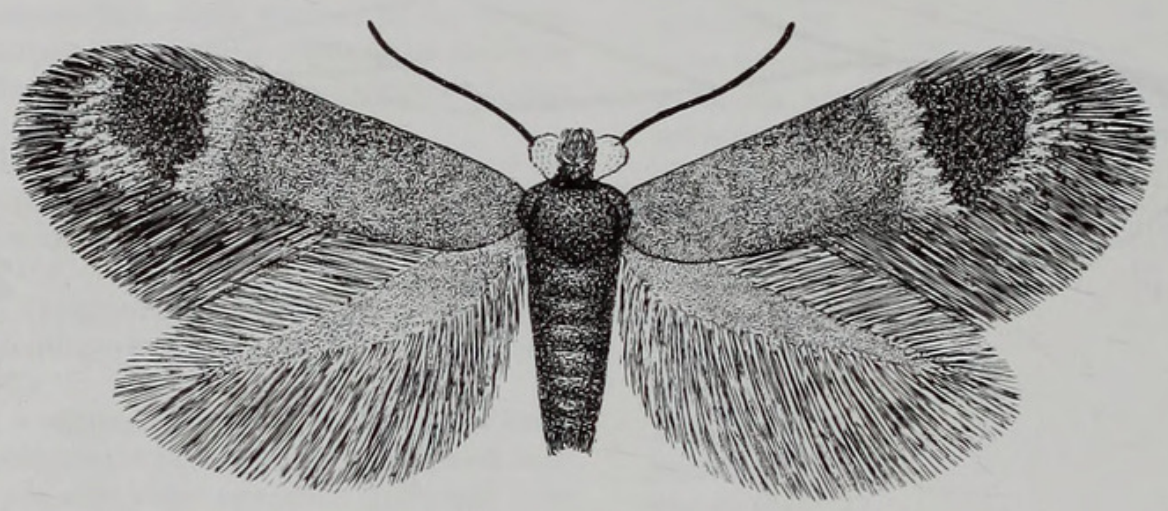

6

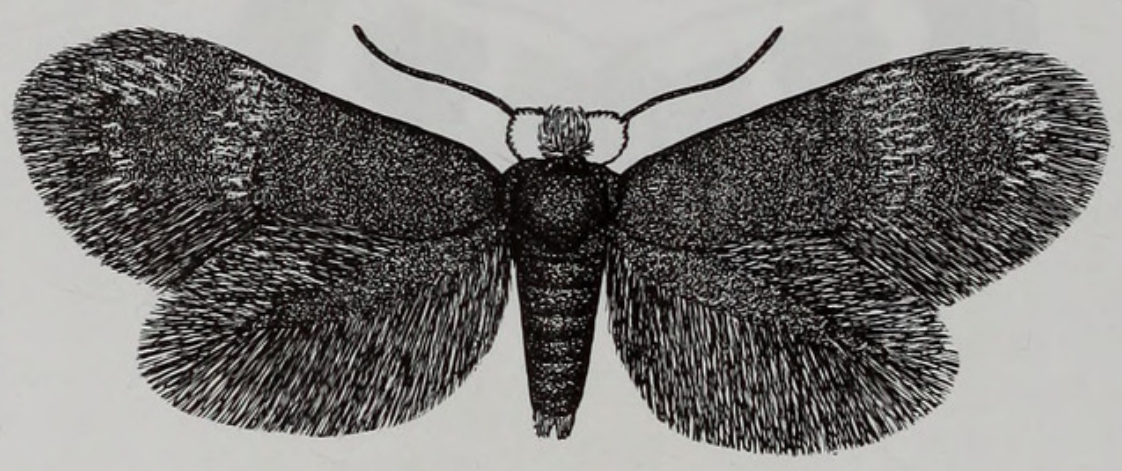

Figs 4-7. Neotropical Nepticulidae. 4, Enteucha acuta; 5, Stigmella montanotropica; 6, S. nubimontana; 7, S. rubeta. 


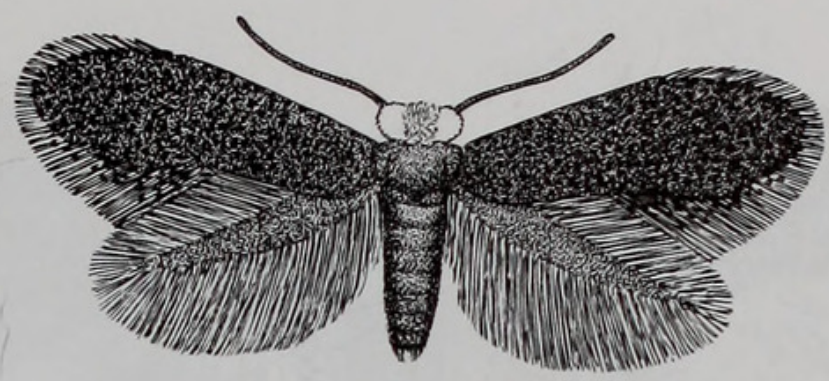

8

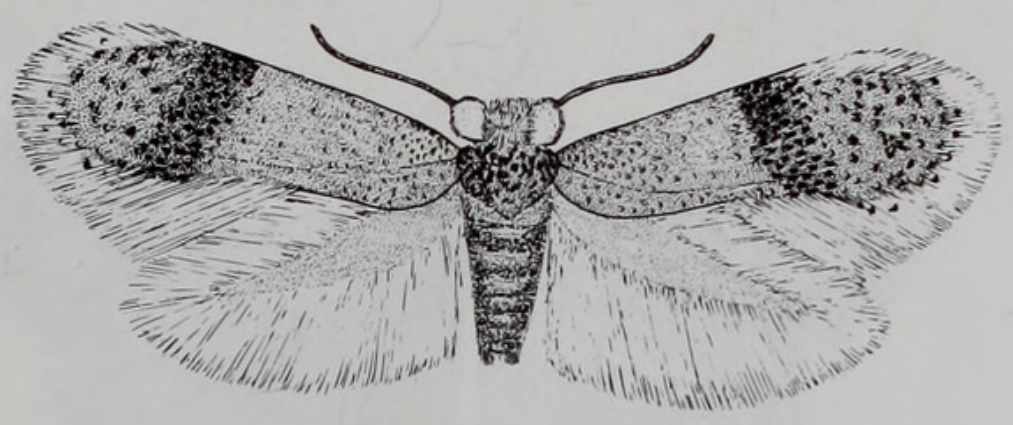

9

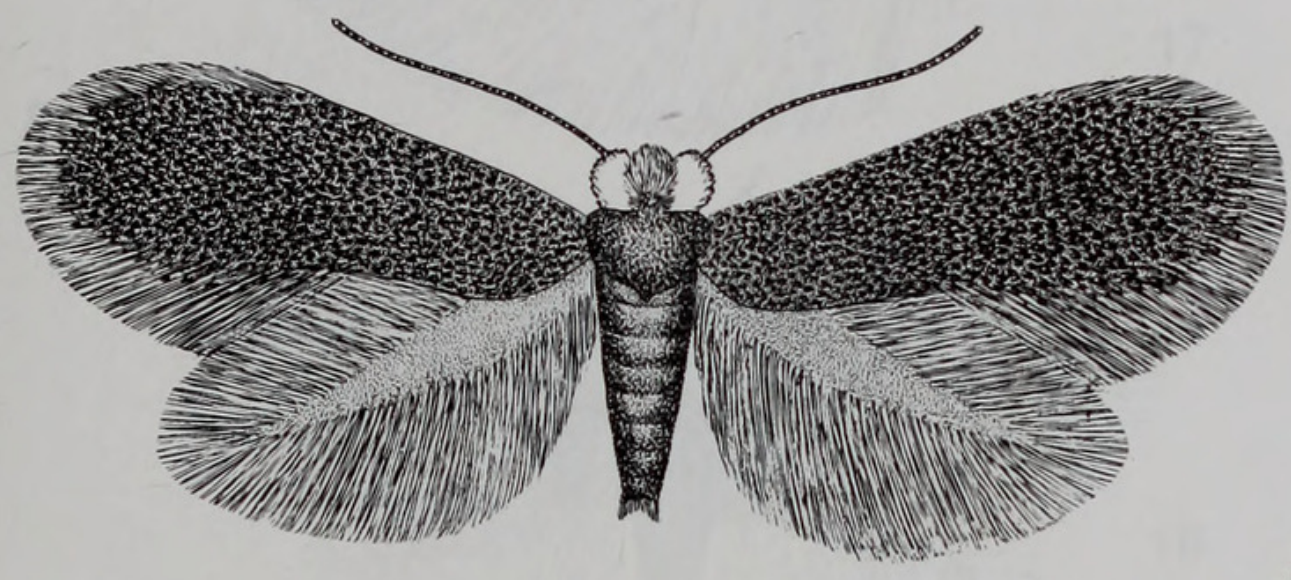

10

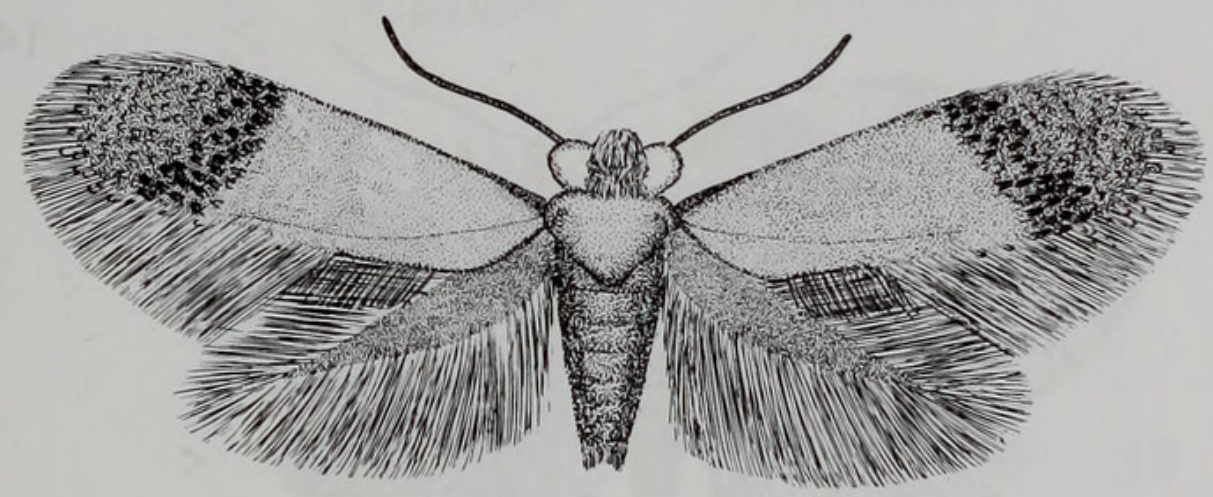

Figs 8-11. Neotropical Nepticulidae. 8, Stigmella austroamericana; 9, Fomoria repanda; 10, F. tabulosa; 11, Acalyptris ecuadoriana. 


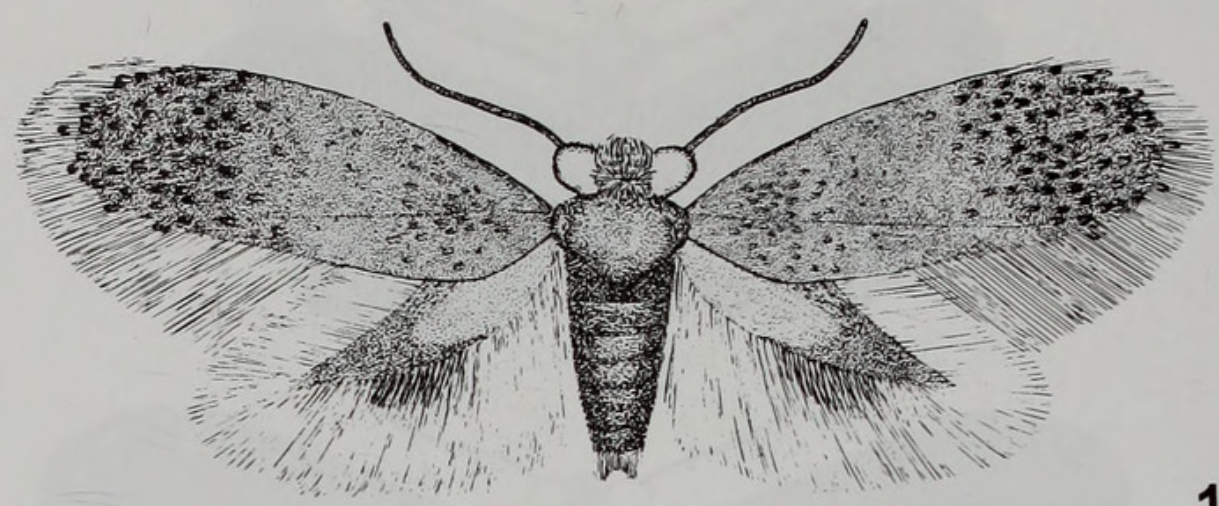

12

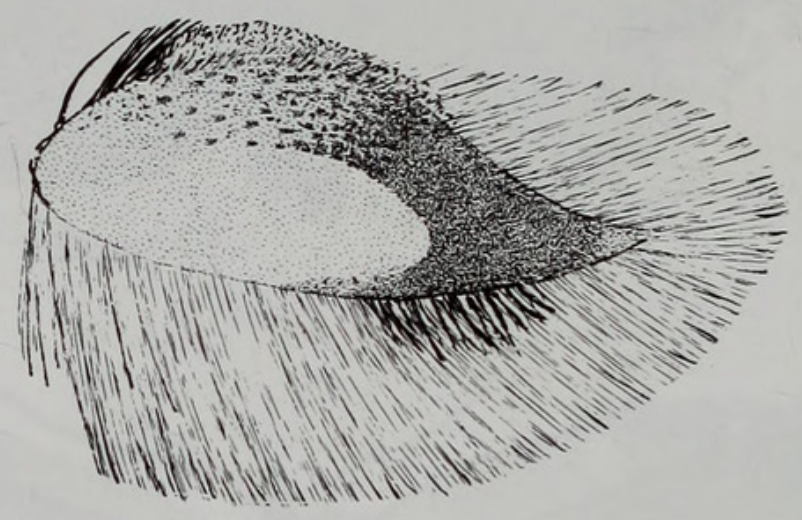

13

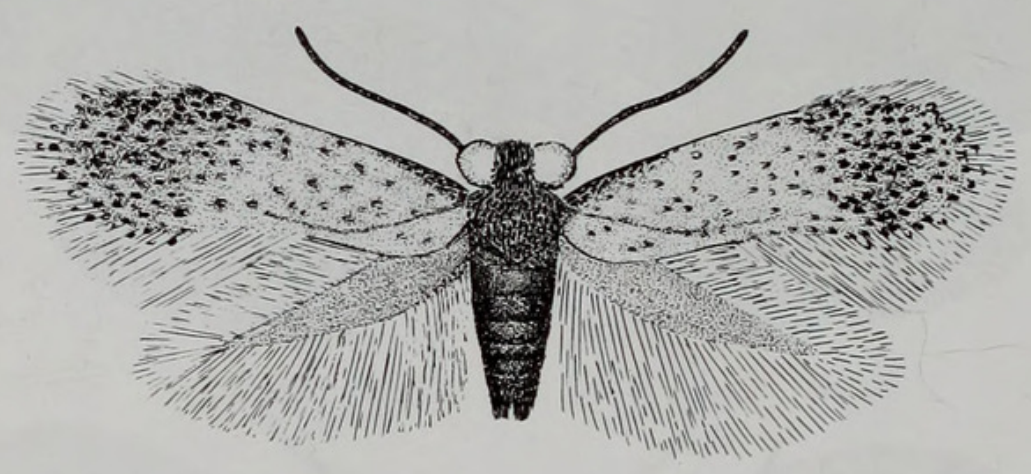

14

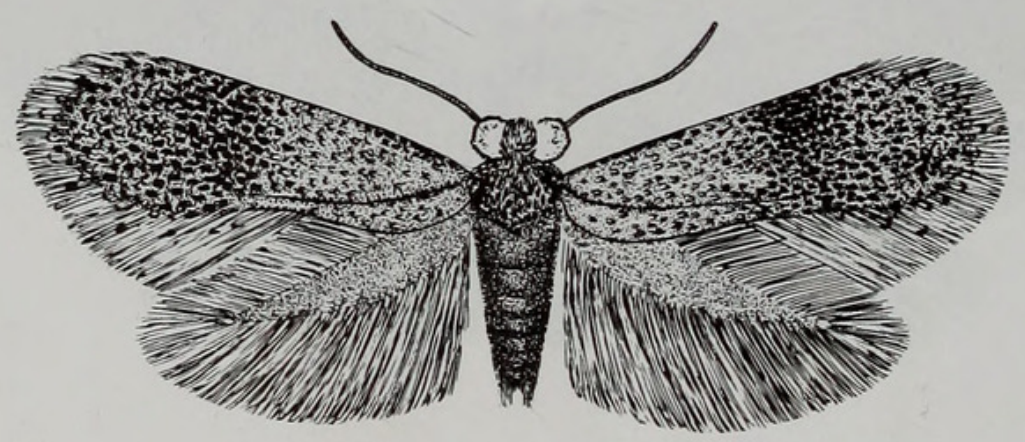

Figs 12-15. Acalyptris species. 12, onorei; 13, same, hindwing; 14, basihastatus; 15, pseudohastatus. 

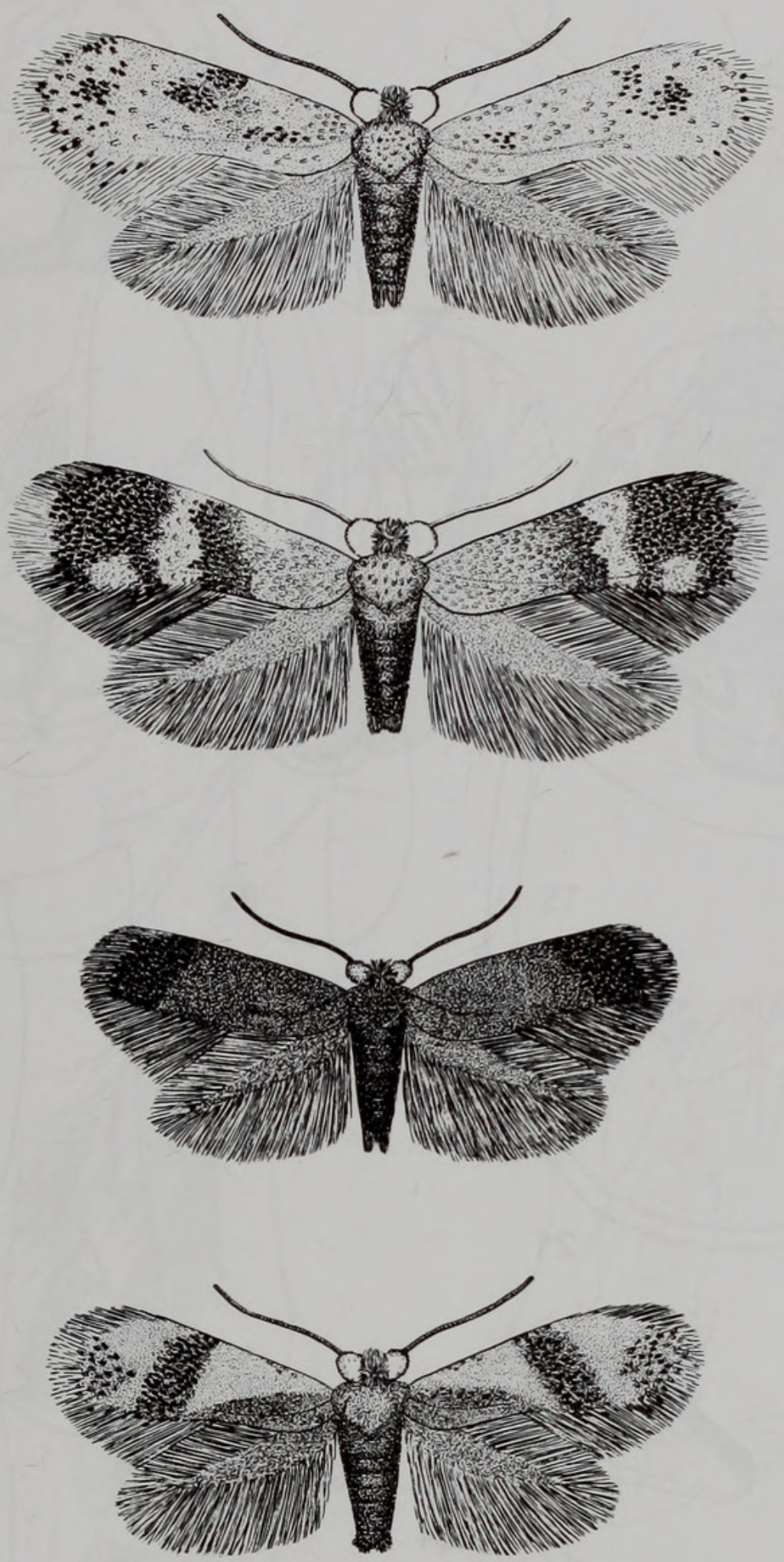

Figs 16-19. Acalyptris species. 16, articulosus; 17 , rotundus; 18 , amazonius; 19 , insolentis. 


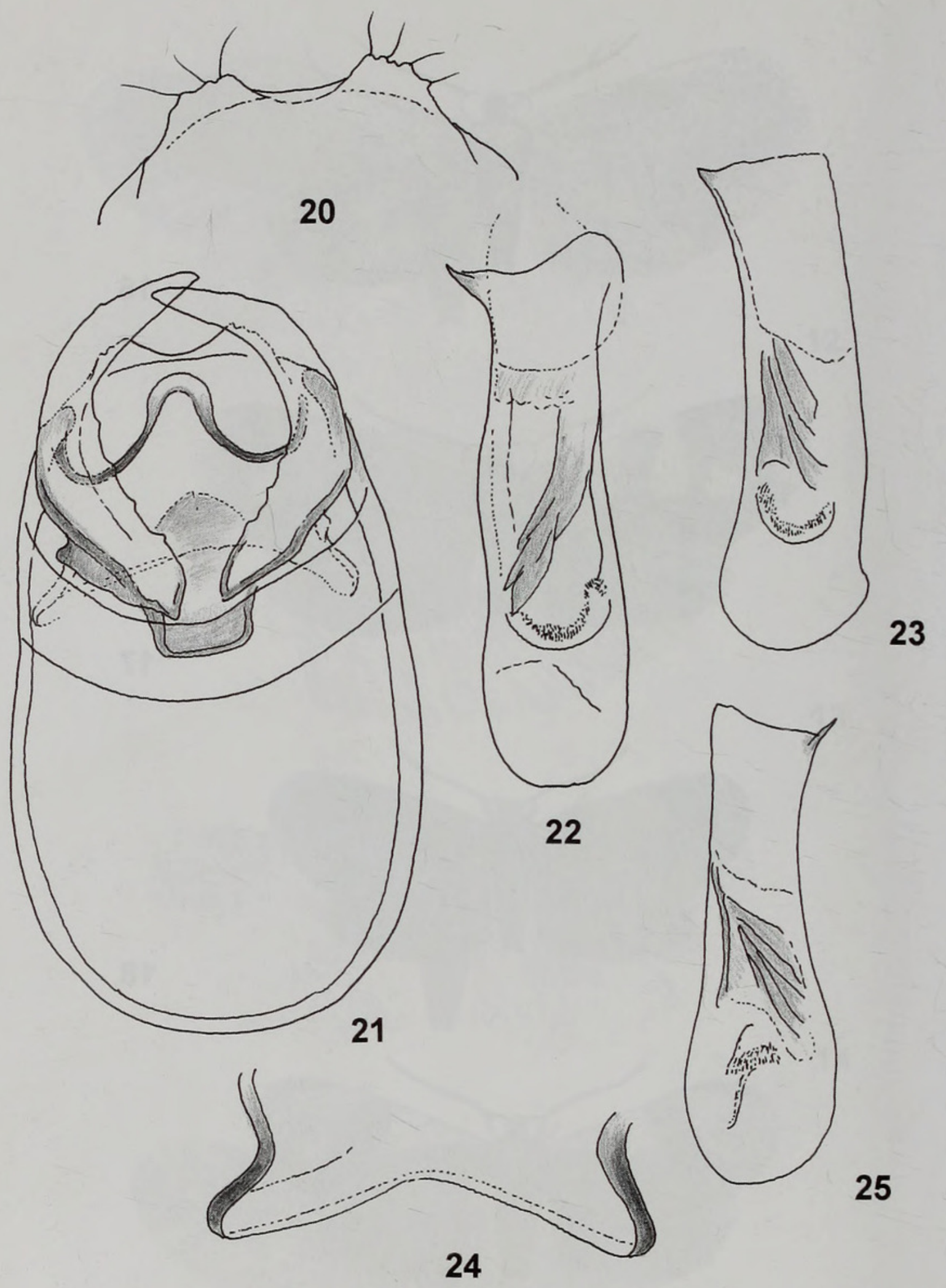

Figs 20-25. Male genitalia of Enteucha guajavae. 20, holotype (AD0340-VPU) uncus; 21, same, capsule; 22, same, aedeagus; 23, paratype (AD0342-VPU) aedeagus; 24, paratype (AD0341-VPU) transtilla; 25, same, aedeagus. Scale: $0.1 \mathrm{~mm}$. 


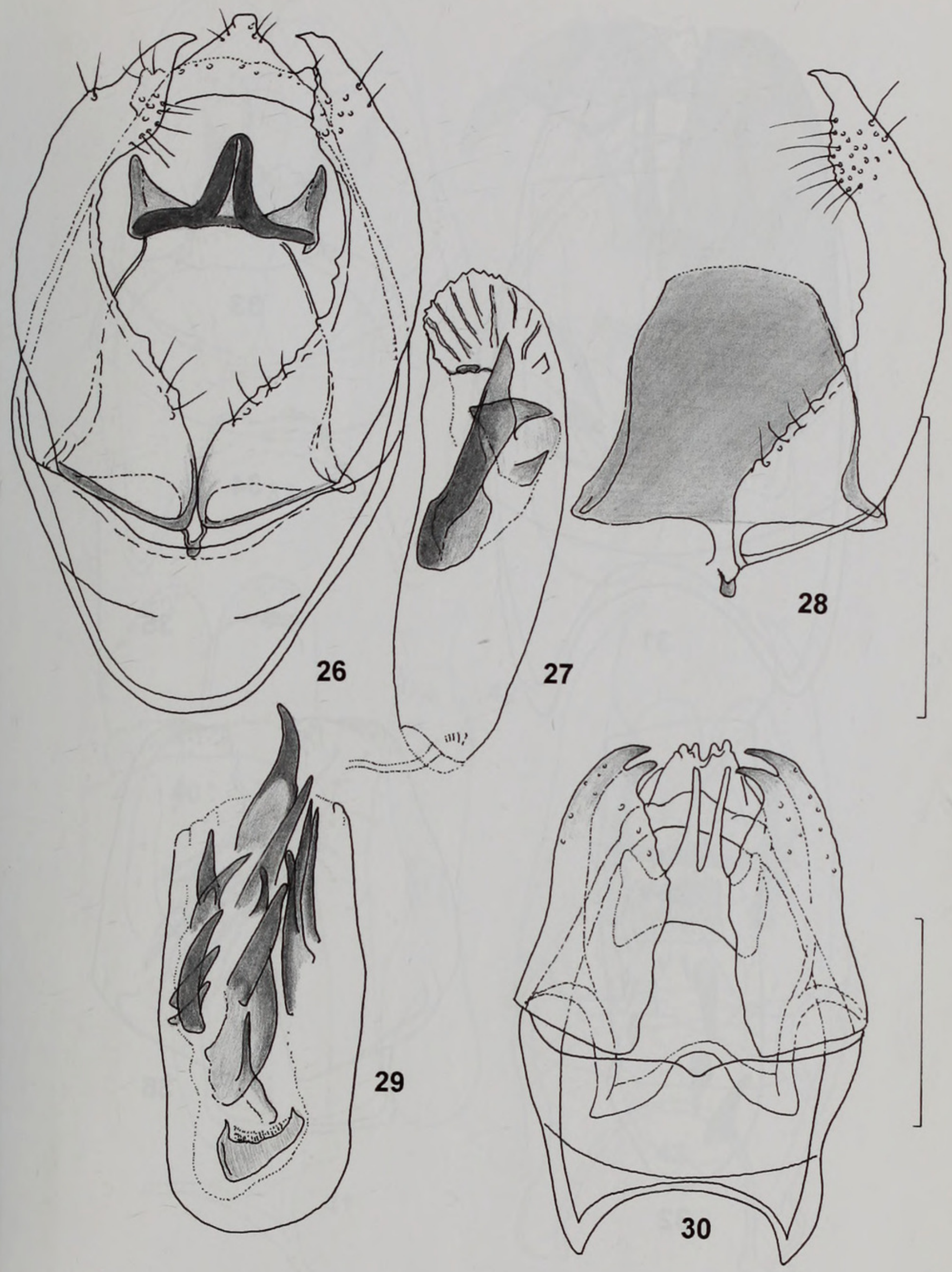

Figs 26-30. Male genitalia of Nepticulidae. 26, Enteucha acuta, holotype (29604-BMNH) capsule; 27, same, aedeagus; 28 , same, right valva and juxta; 29, Stigmella montanotropica, paratype, (29618-BMNH) aedeagus; 30, same, capsule. Scale: $0.1 \mathrm{~mm}$. 

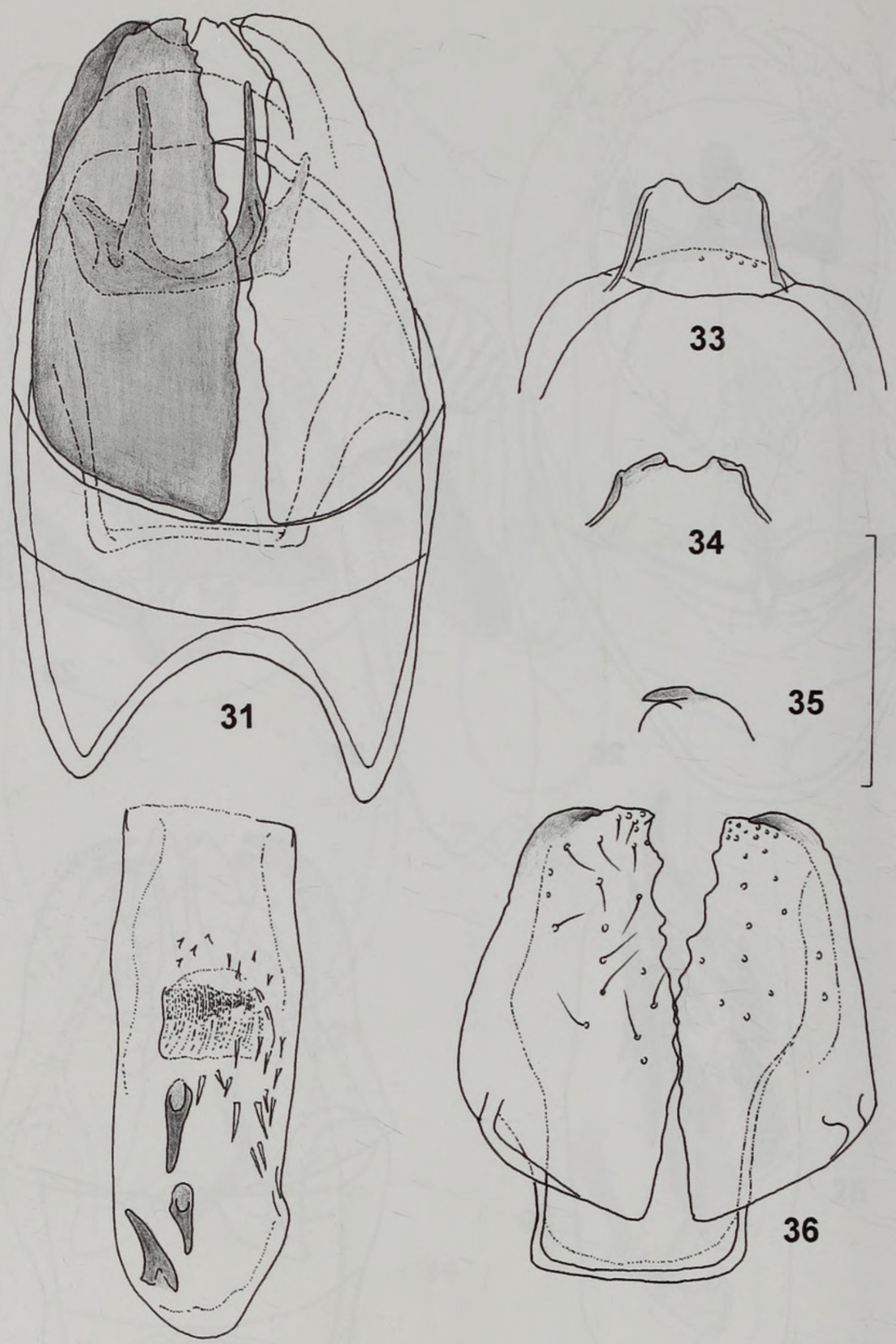

32

Figs 31-36. Male genitalia of Stigmella nubimontana. 31, holotype (29614-BMNH) capsule; 32, same, aedeagus; 33, paratype (AD0322-VPU) uncus; 34, paratype (AD0321-VPU) uncus; 35, paratype (AD0321-VPU) apex of valva; 36, paratype (AD0322-VPU) both valvae and transtilla. Scale: $0.1 \mathrm{~mm}$. 

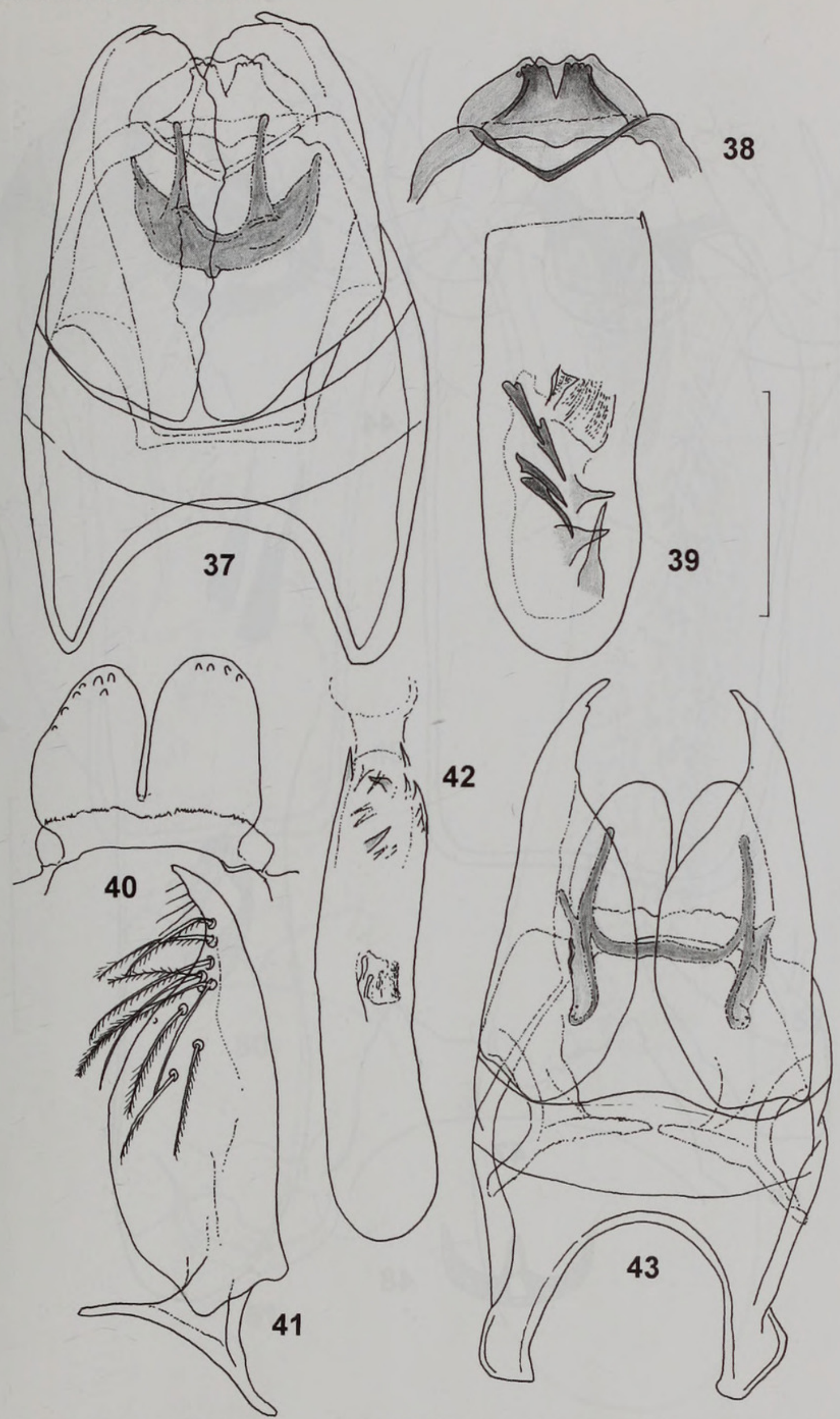

Figs 37-43. Male genitalia of Stigmella. 37, rubeta, holotype (29616-BMNH) capsule; 38, same, tegumen + uncus; 39 , same, aedeagus; 40, austroamericana, holotype (29613-BMNH) uncus; 41, same, valva; 42, same, aedeagus; 43, same, capsule. Scale: $0.1 \mathrm{~mm}$. 


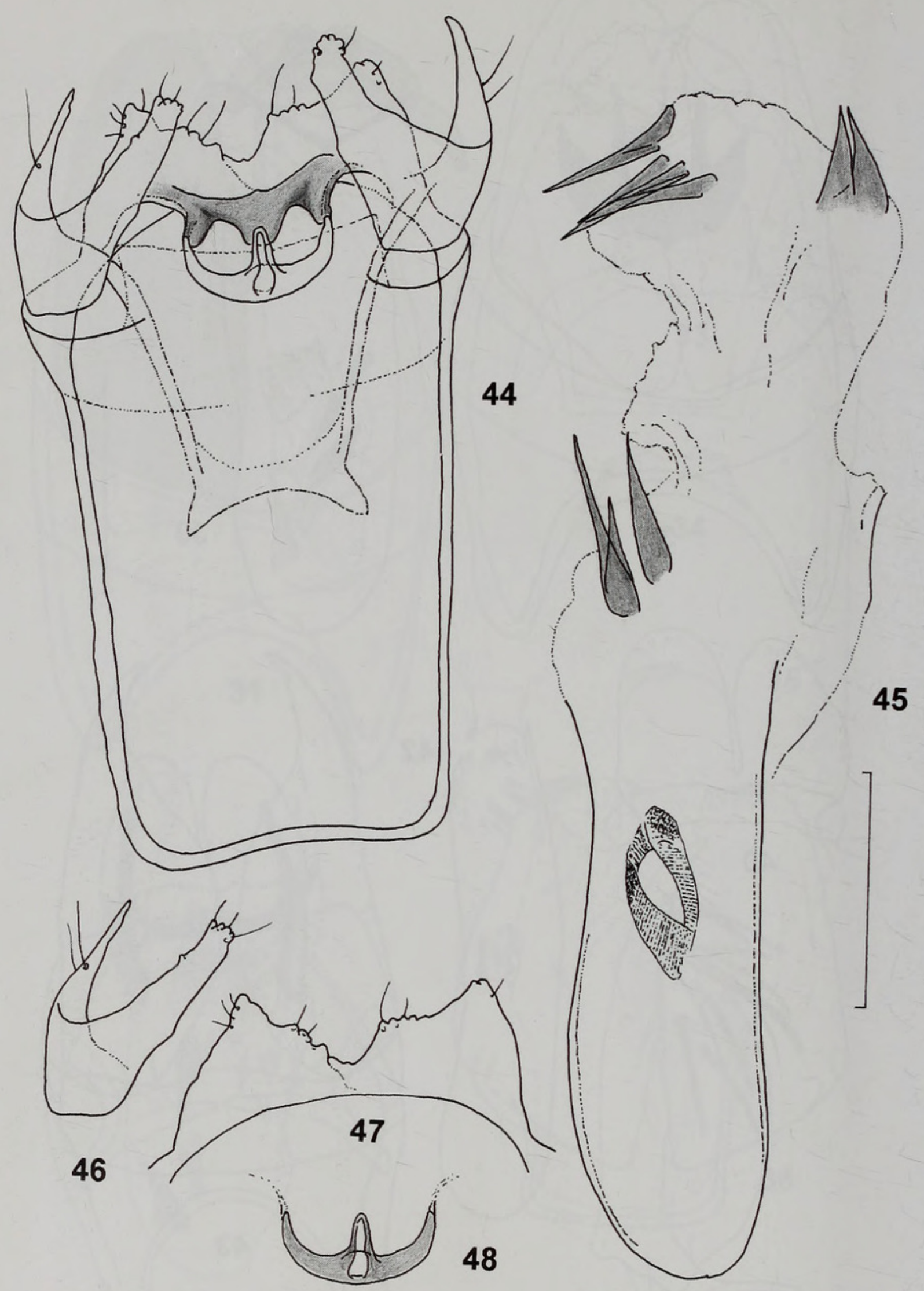

Figs 44-48. Male genitalia of Fomoria repanda, holotype (29603-BMNH). 44, capsule; 45, aedeagus; 46, valva, 47, pseuduncus; 48 , gnathos. Scale: $0.1 \mathrm{~mm}$. 


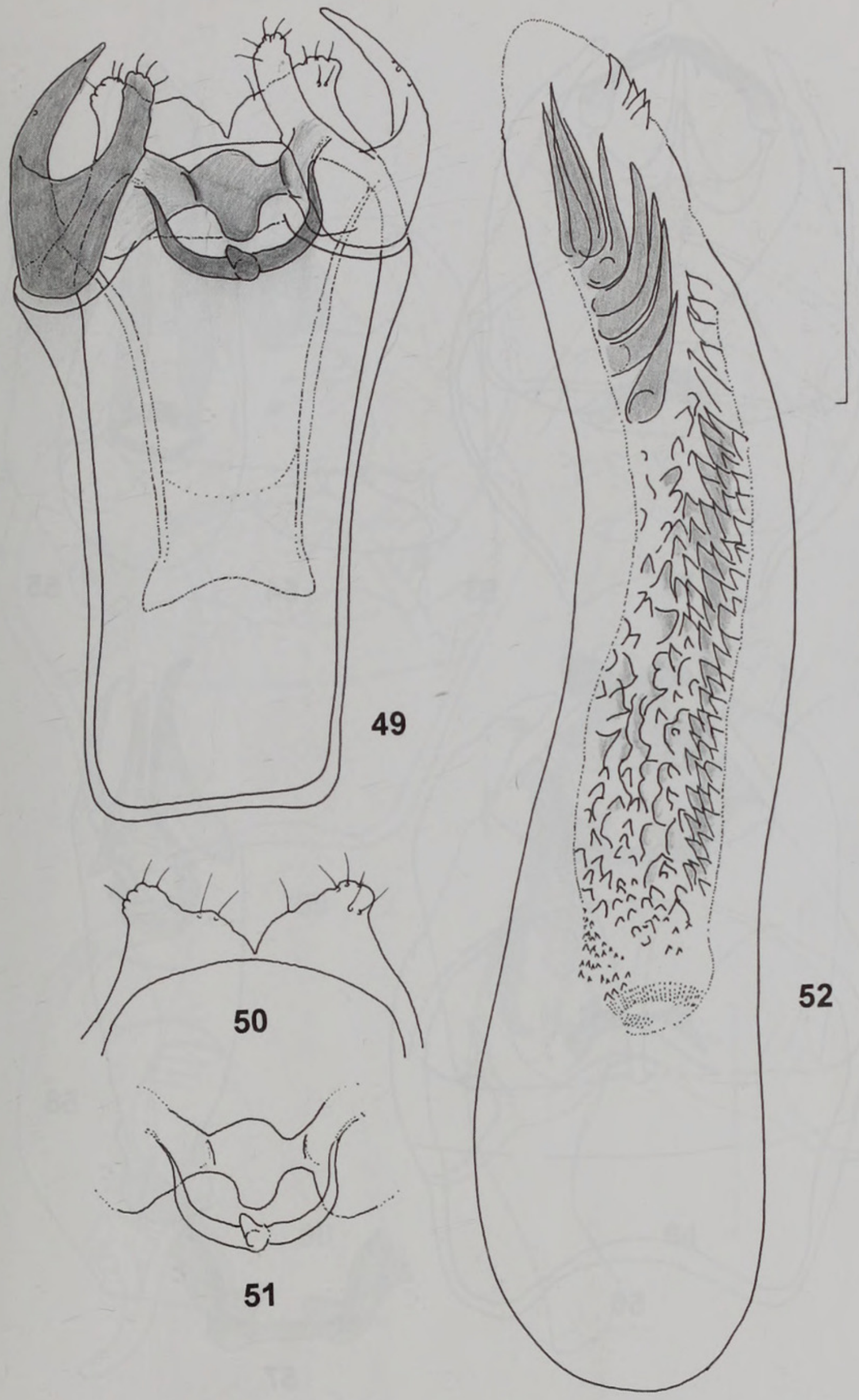

Figs 49-52. Male genitalia of Fomoria repanda, paratype (AD0315-VPU). 49, capsule; 50, pseuduncus; 51, uncus + gnathos; 52 , aedeagus. Scale: $0.1 \mathrm{~mm}$. 

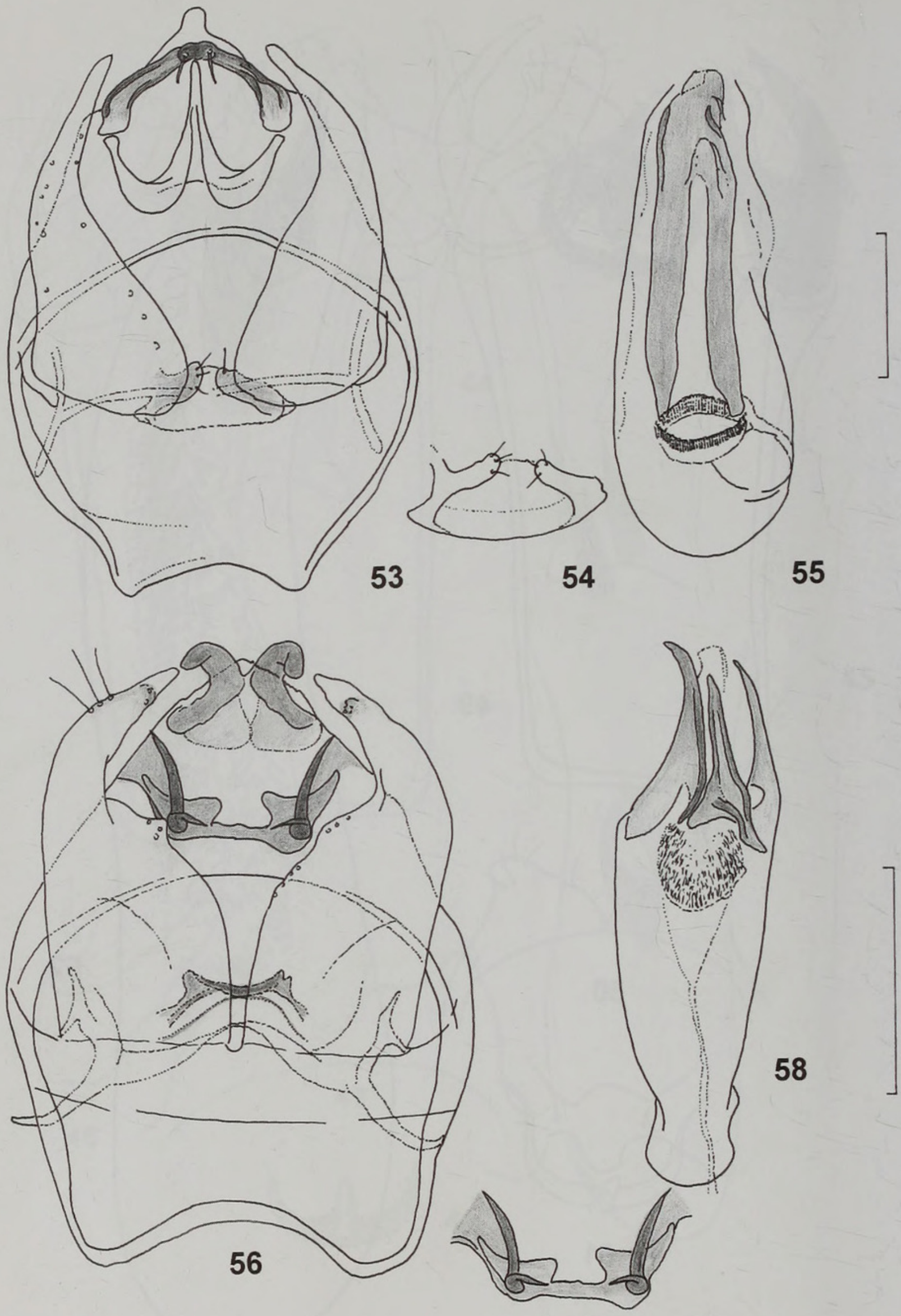

58

57

Figs 53-58. Male genitalia of Nepticulidae. 53, Fomoria tabulosa, holotype (29625-BMNH) capsule; 54, same, juxta; 55, same, aedeagus; 56, Acalyptris ecuadoriana, holotype (29624-BMNH) capsule; 57, same, gnathos; 58, same, aedeagus. Scale: $0.1 \mathrm{~mm}$. 


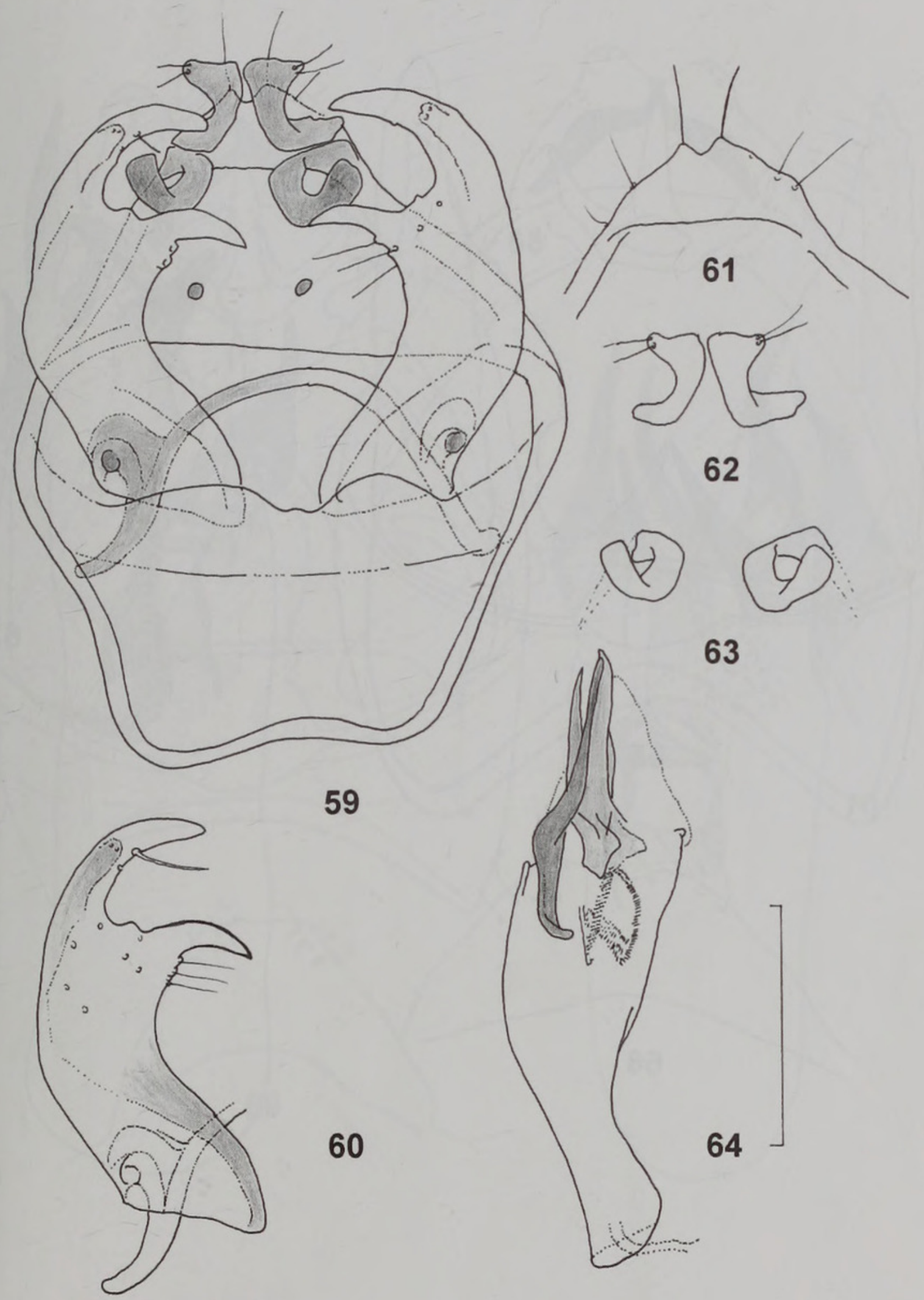

Figs 59-64. Male genitalia of Acalyptris onorei, holotype (29623-BMNH). 59, capsule; 60, valva; 61, pseuduncus; 62, paired uncus; 63 , paired gnathos; 64 , aedeagus. Scale: $0.1 \mathrm{~mm}$. 


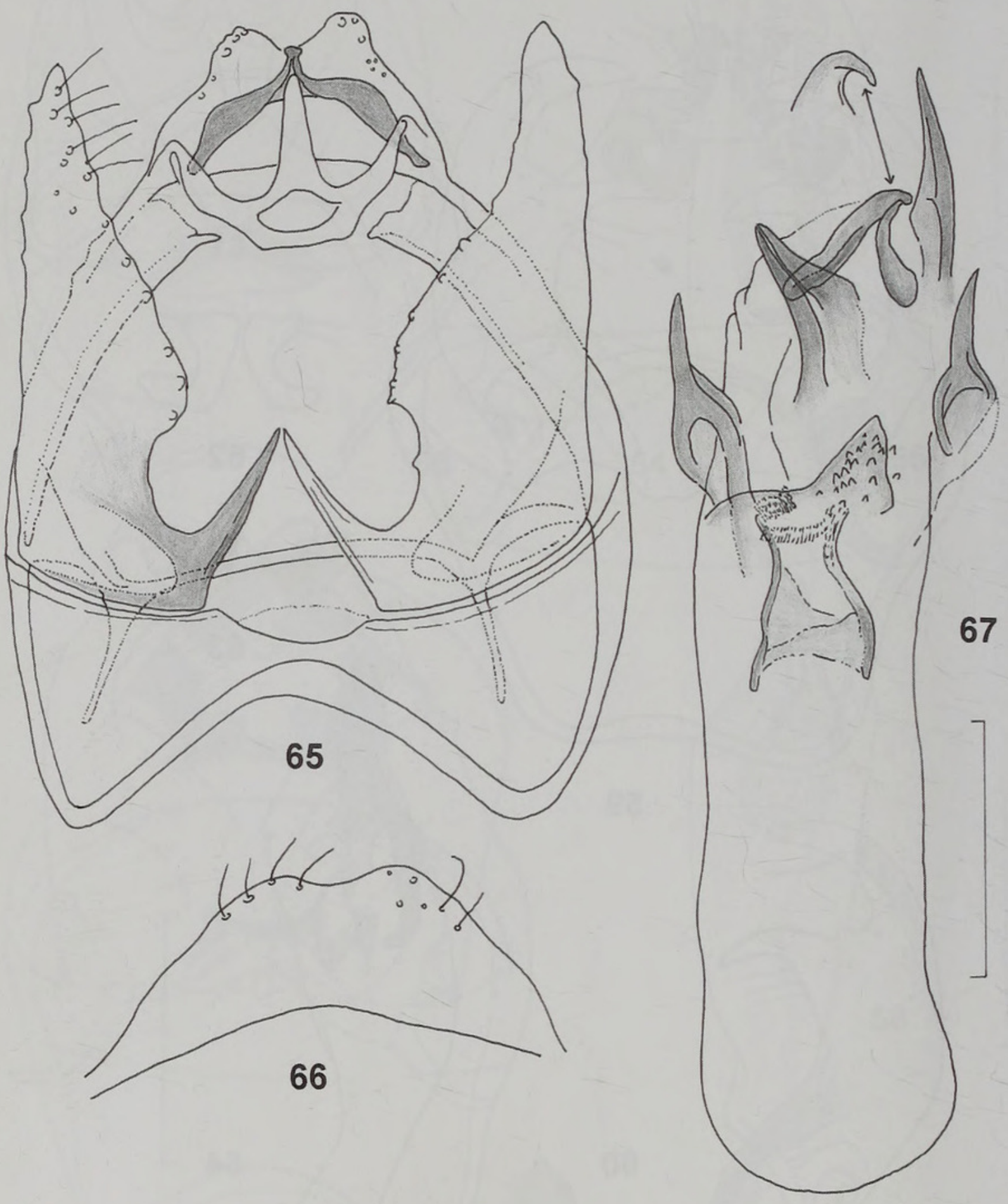

Figs 65-67. Male genitalia of Acalyptris basihastatus. 65, holotype (29605-BMNH) capsule; 66, paratype, (29606-BMNH) pseuduncus; 67, holotype (29605-BMNH) aedeagus. Scale: $0.1 \mathrm{~mm}$. 


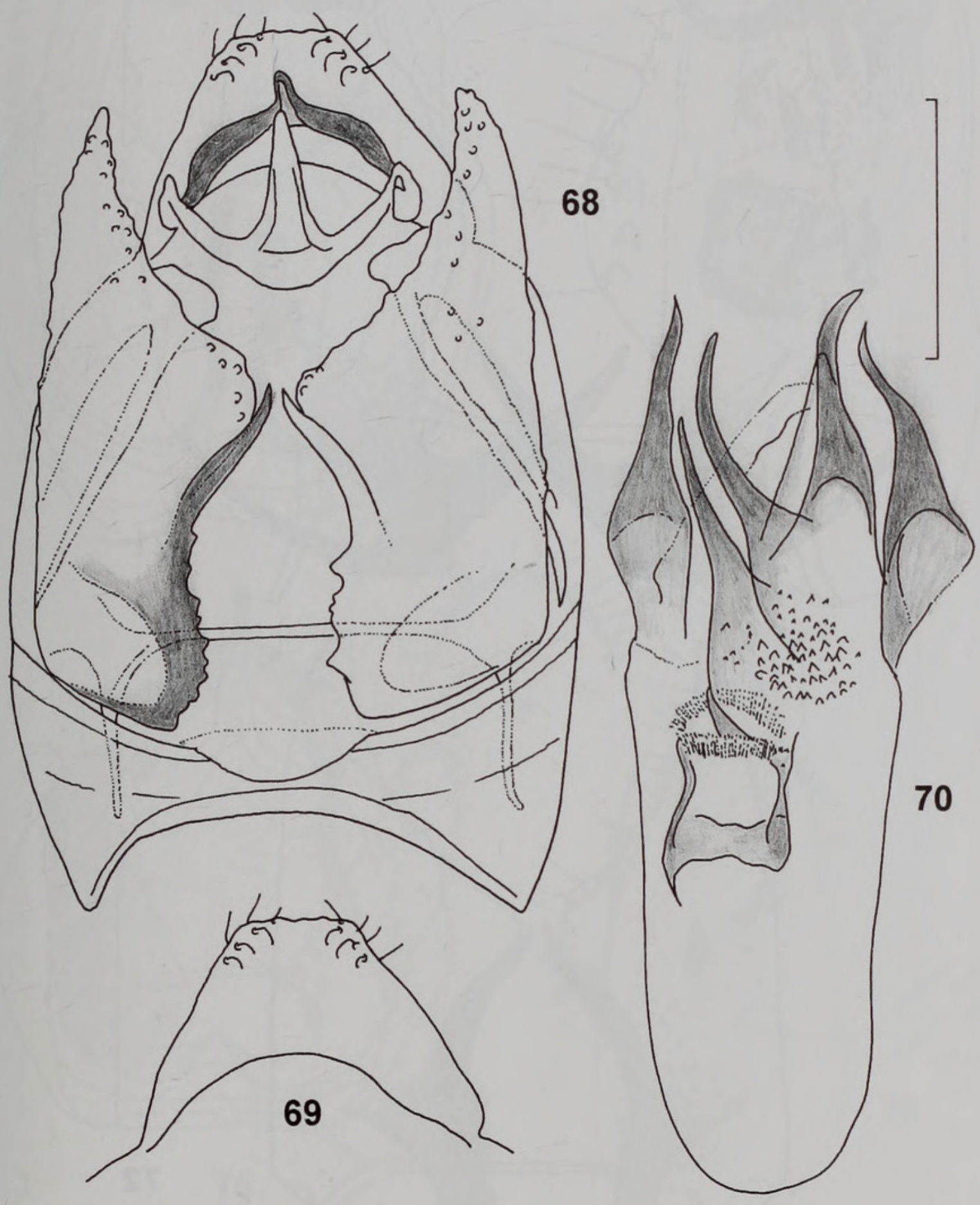

Figs 68-70. Male genitalia of Acalyptris pseudohastatus, holotype (29607-BMNH). 68, capsule; 69, pseuduncus; 70, aedeagus. Scale: $0.1 \mathrm{~mm}$. 


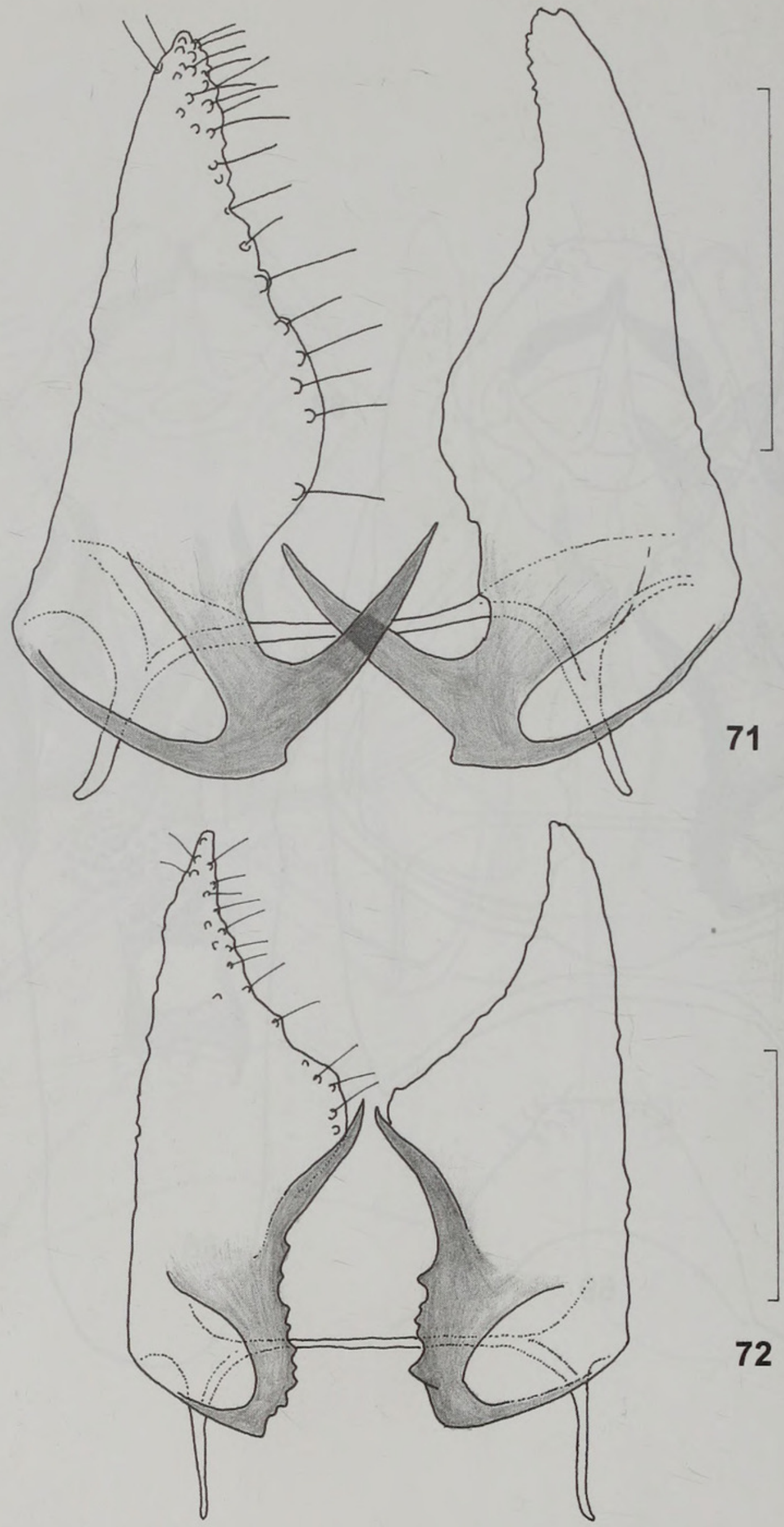

Figs 71, 72. Valvae of Acalyptris. 71, basihastatus, paratype (29606-BMNH); 72, pseudohastatus, holotype (29607BMNH). Scale: $0.1 \mathrm{~mm}$. 


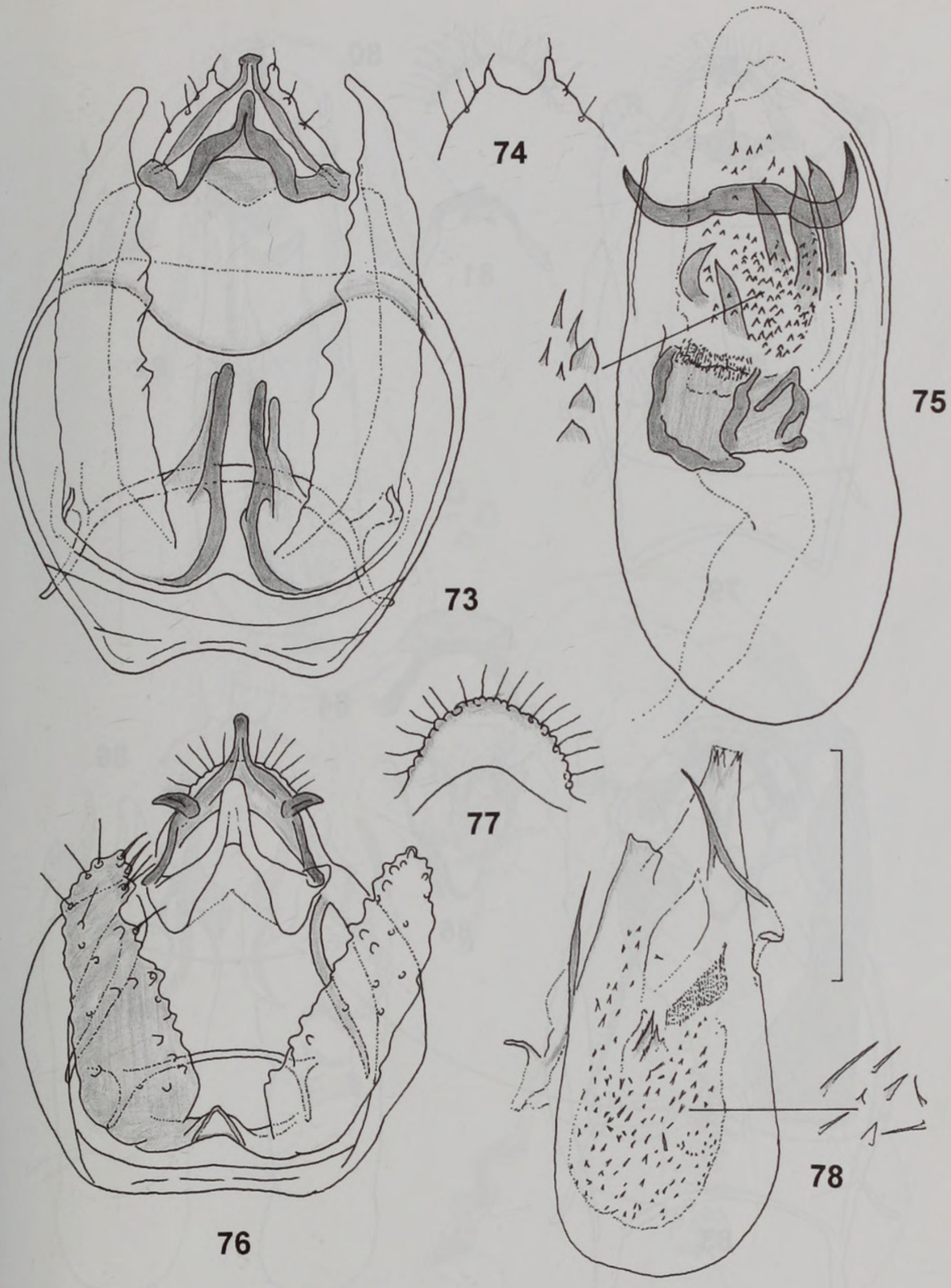

Figs 73-78. Male genitalia of Acalyptris. 73, articulosus, holotype (29610-BMNH) capsule; 74, same, pseuduncus; 75, same, aedeagus; 76, rotundus, holotype (29611-BMNH) capsule; 77, same, pseuduncus; 78, same, aedeagus. Scale: $0.1 \mathrm{~mm}$. 

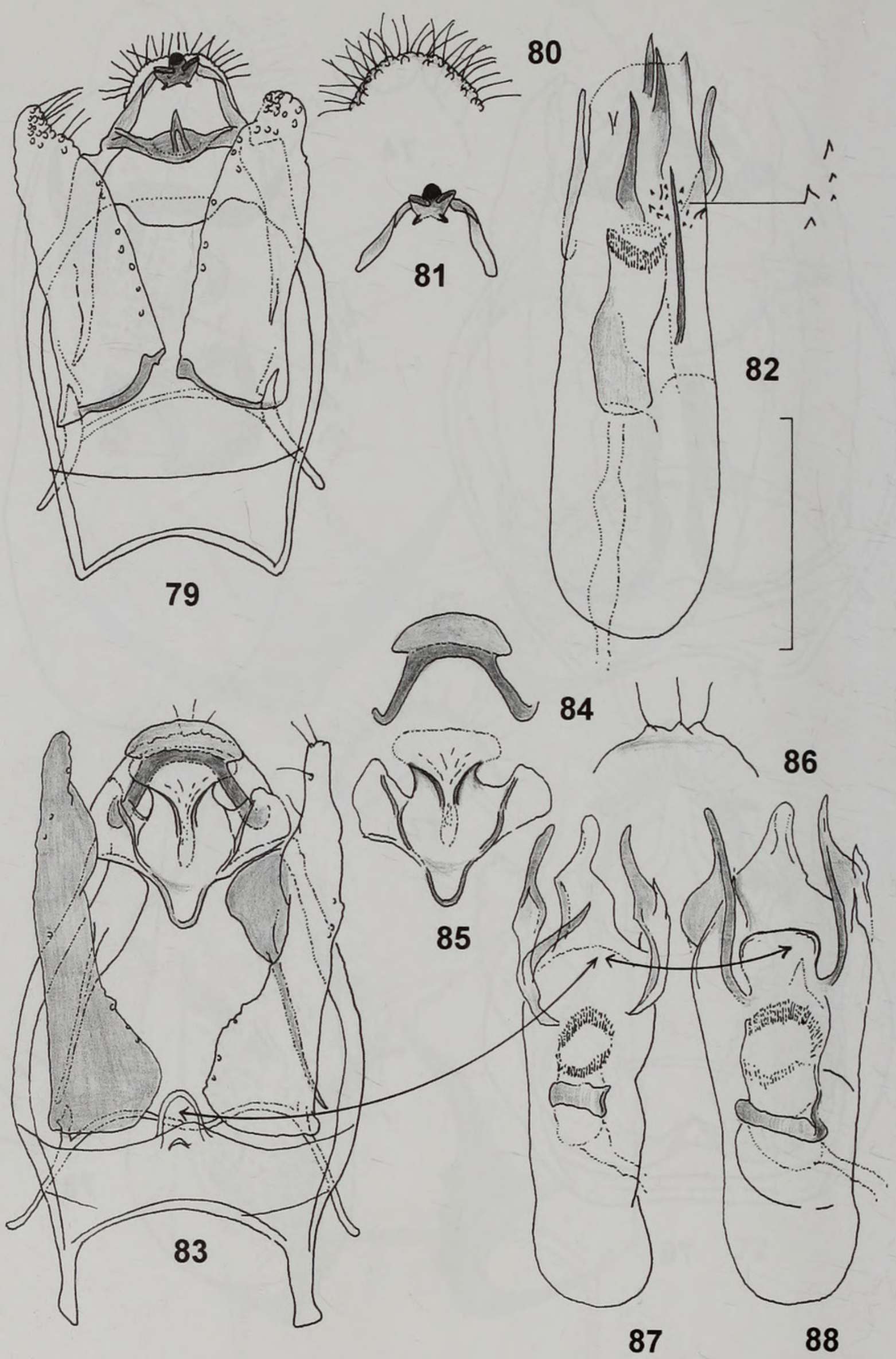

Figs 79-88. Male genitalia of Acalyptris. 79, amazonius, holotype (29612-BMNH) capsule; 80, same, pseuduncus; 81, same, uncus; 82, same, aedeagus; 83, insolentis, holotype (29621-BMNH) capsule; 84, same, uncus; 85, same, gnathos; 86, same, pseuduncus; 87 , same, aedeagus with broken ventral lobe (juxta); 88, paratype (29622-BMNH) aedeagus. Scale: $0.1 \mathrm{~mm}$. 


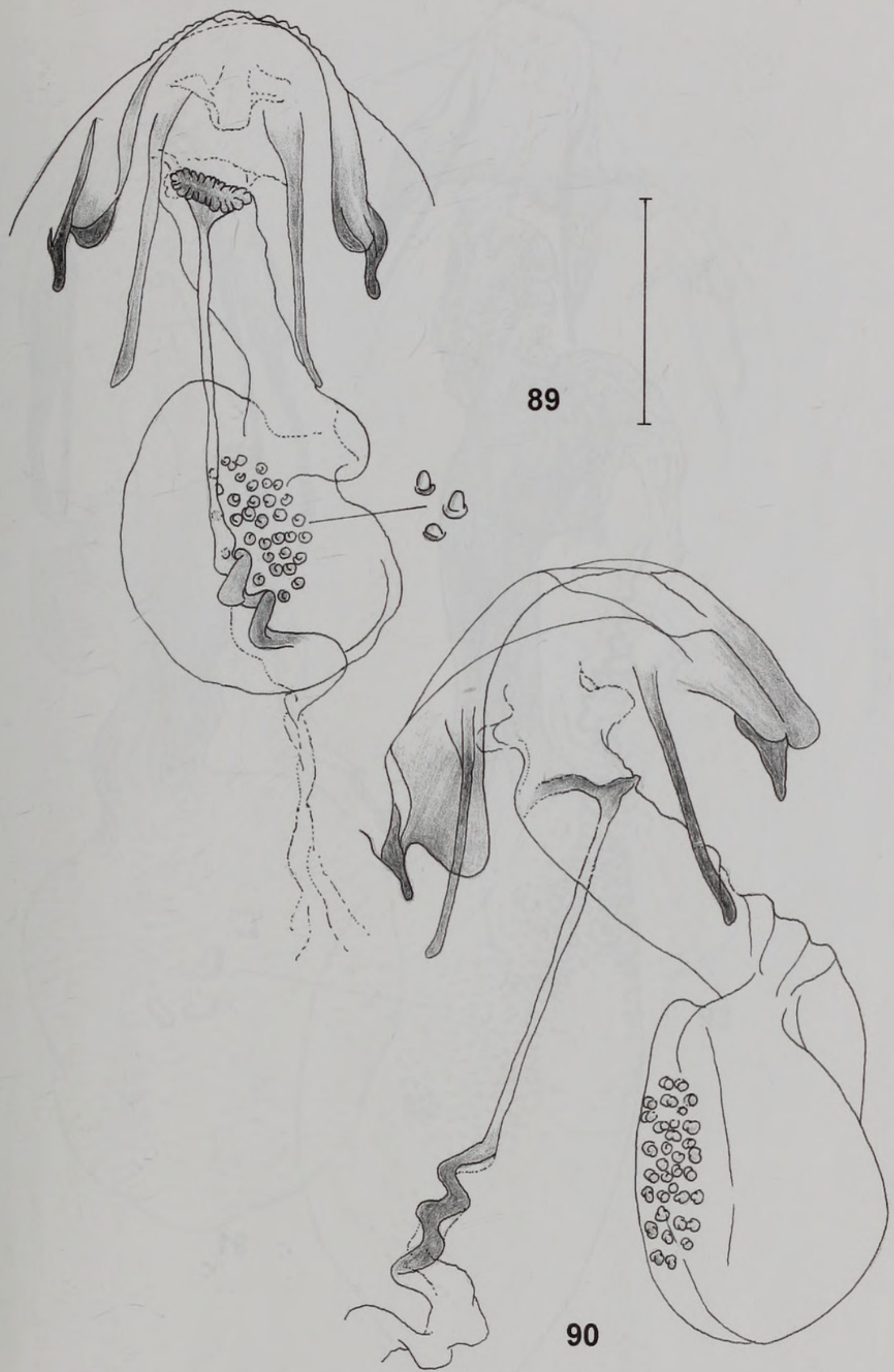

Figs 89, 90. Female genitalia of Enteucha guajavae. 89, paratype (AD0344-VPU); 90, paratype (AD0343-VPU). Scale: $0.1 \mathrm{~mm}$. 


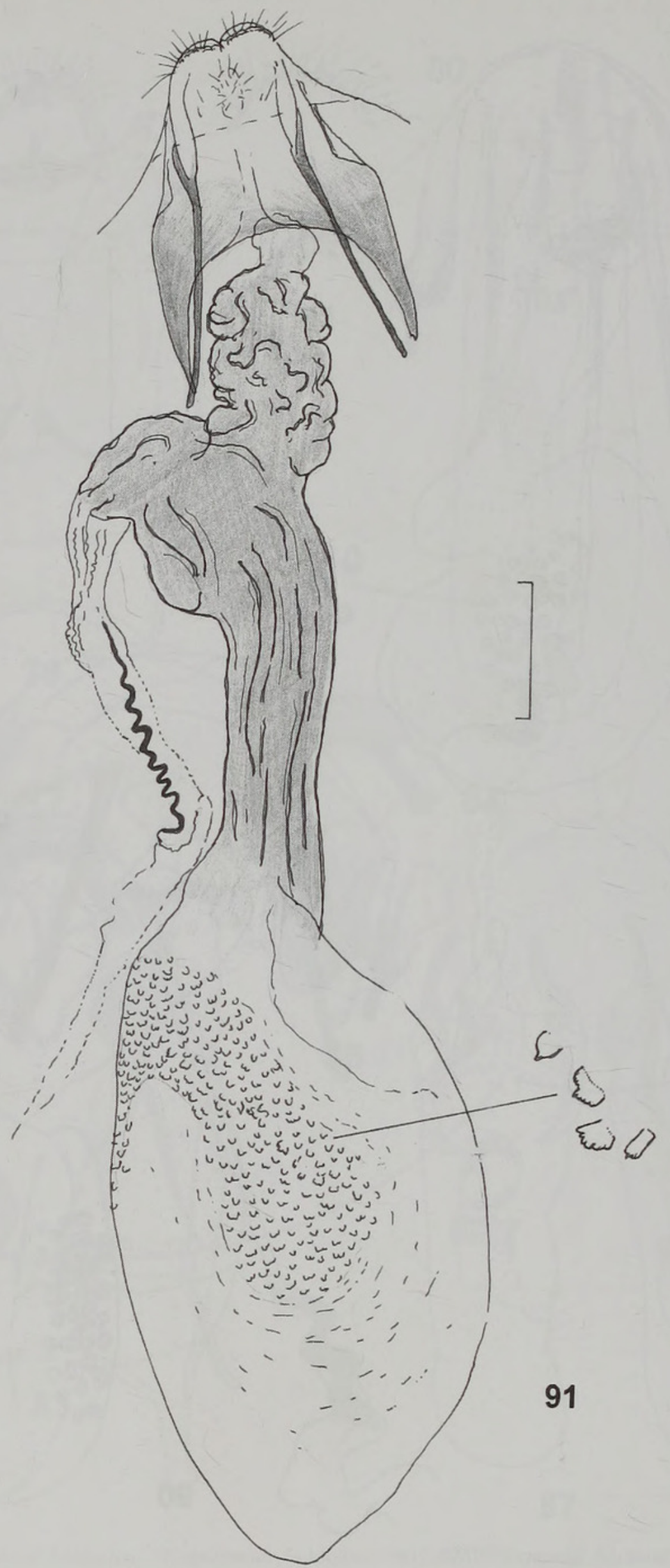

Fig. 91. Female genitalia of Stigmella montanotropica, holotype (29619-BMNH). Scale: $0.1 \mathrm{~mm}$. 


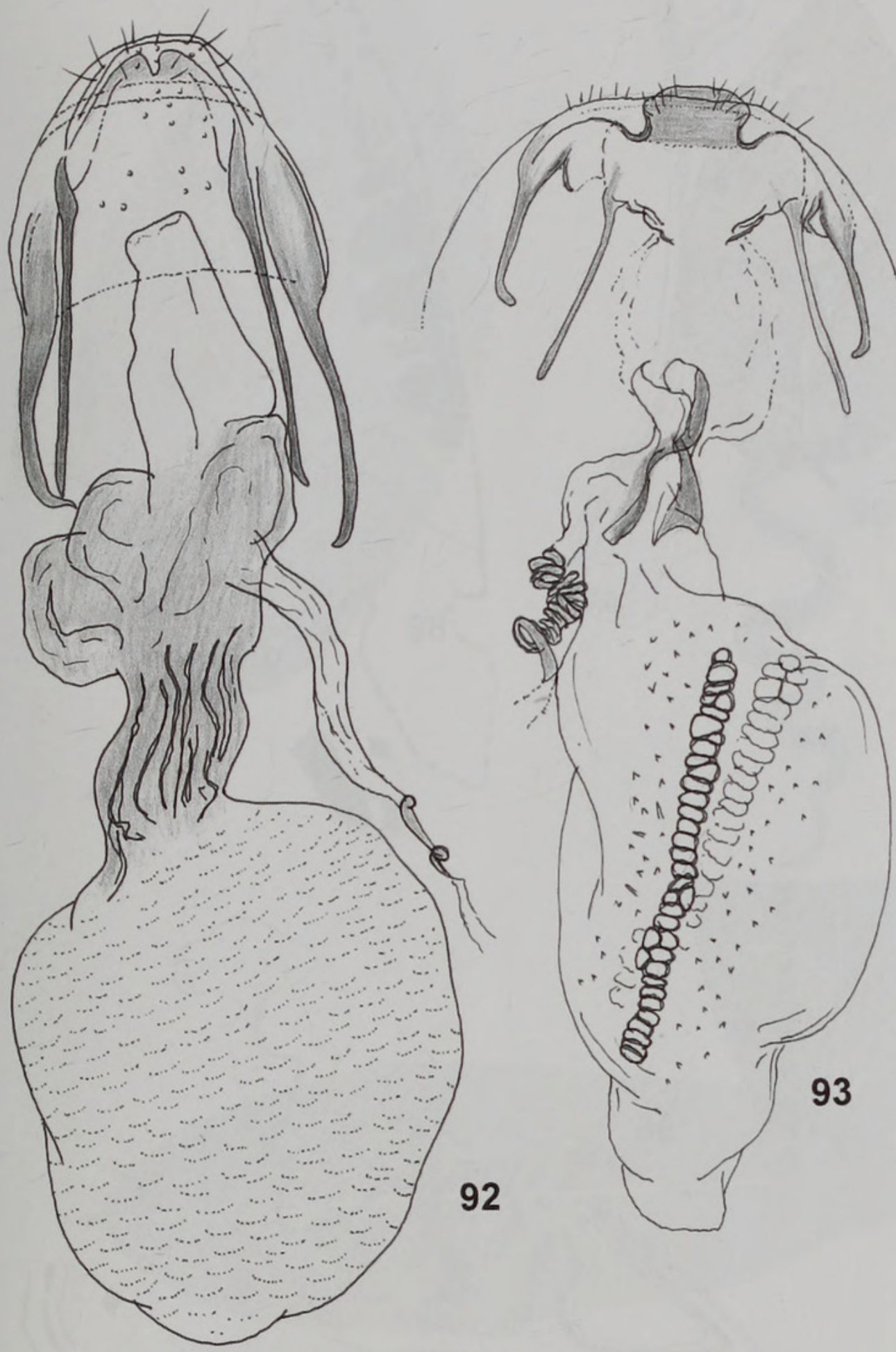

Figs 92, 93. Female genitalia of Nepticulidae. 92, Stigmella rubeta, paratype (29617-BMNH); 93, Acalyptris amazonius, specimen excluded from type series (AD0330-VPU). Scale: $0.1 \mathrm{~mm}$. 

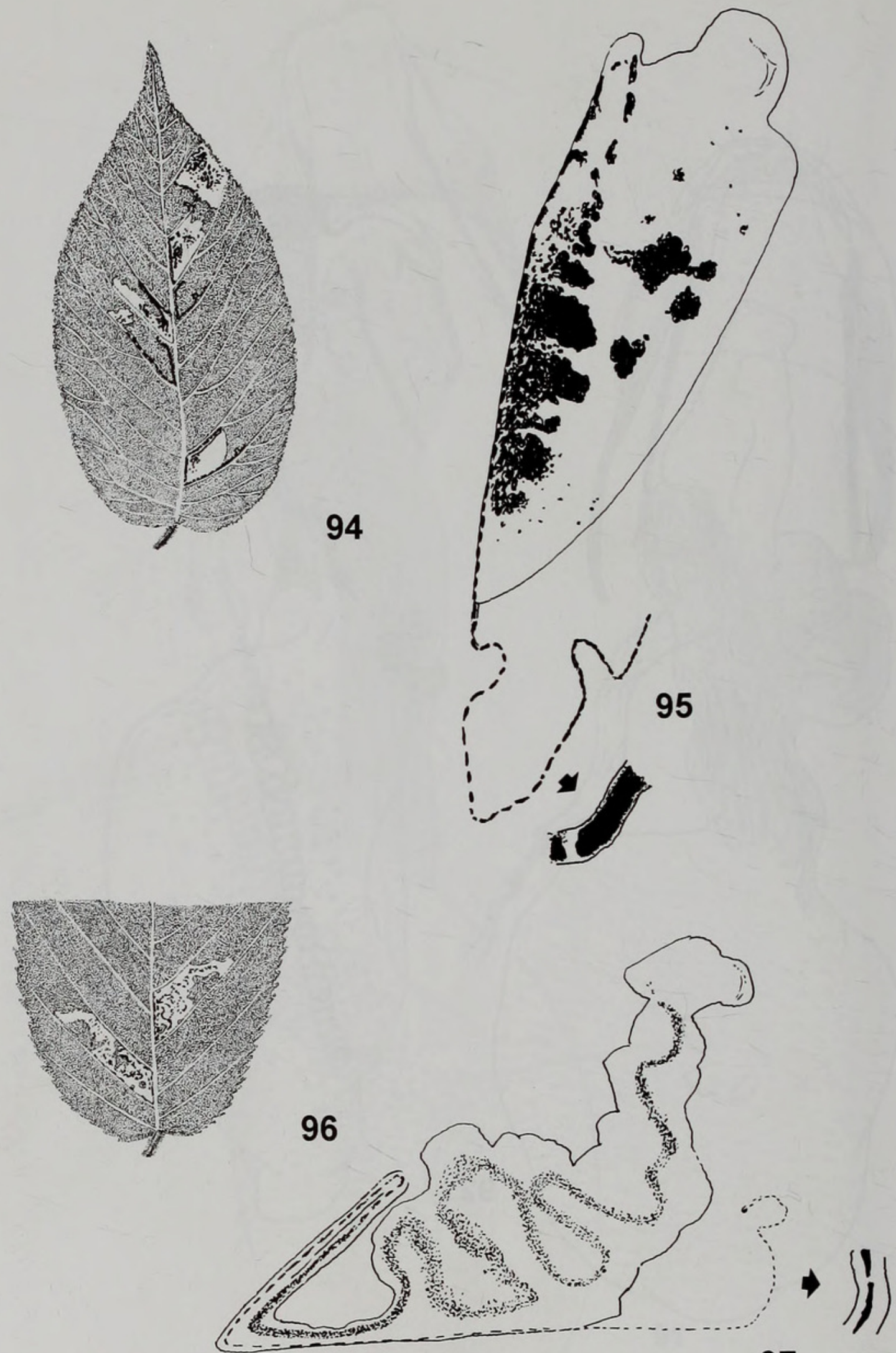

Figs 94-97. Mines of Stigmella species on Rubus spp. from Ecuador. 94, nubimontana, damaged leaf with a few mines, high Andes, Papallacta, sample no. 4630-VPU; 95, same, combined mine (gallery + blotch) showing frass distribution; 96, rubeta, damaged leaf with two mines, tropical western slopes of Andes, Tandapi, sample no. 4629-VPU; 97, same, combined mine (gallery + blotch) showing frass distribution. 

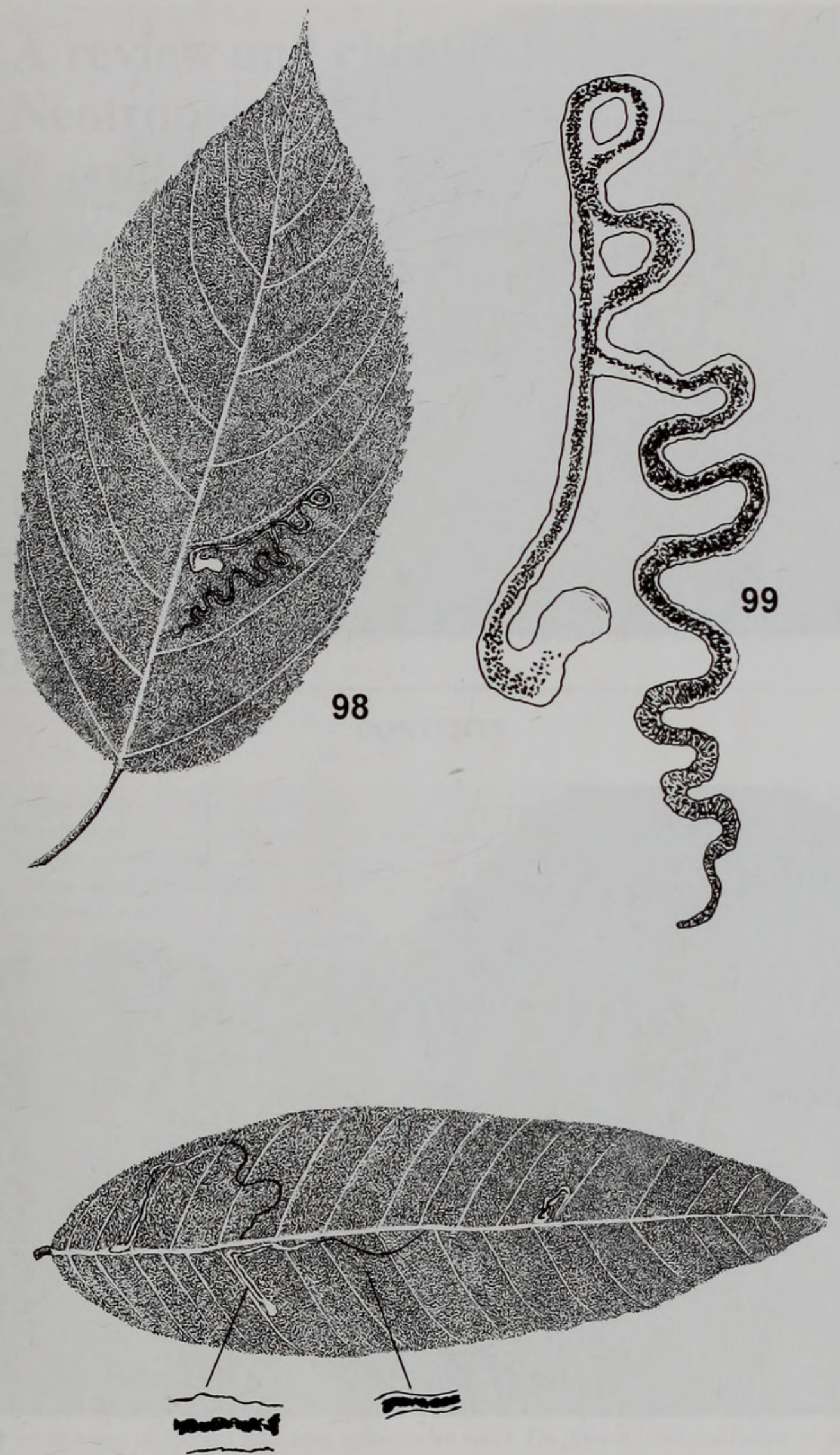

100

Figs 98-100. Mines of Nepticulidae. 98, Stigmella montanotropica, damaged leaf of Acalypha with a sinuous mine, western slopes of Andes, Tandapi, sample no. 4628-VPU; 99, same, gallery showing frass distribution; 100, Enteucha guajavae, damaged leaf of Psidium guajava with mines, western foothills of Andes, Bucay, sample no. 4722-VPU. 

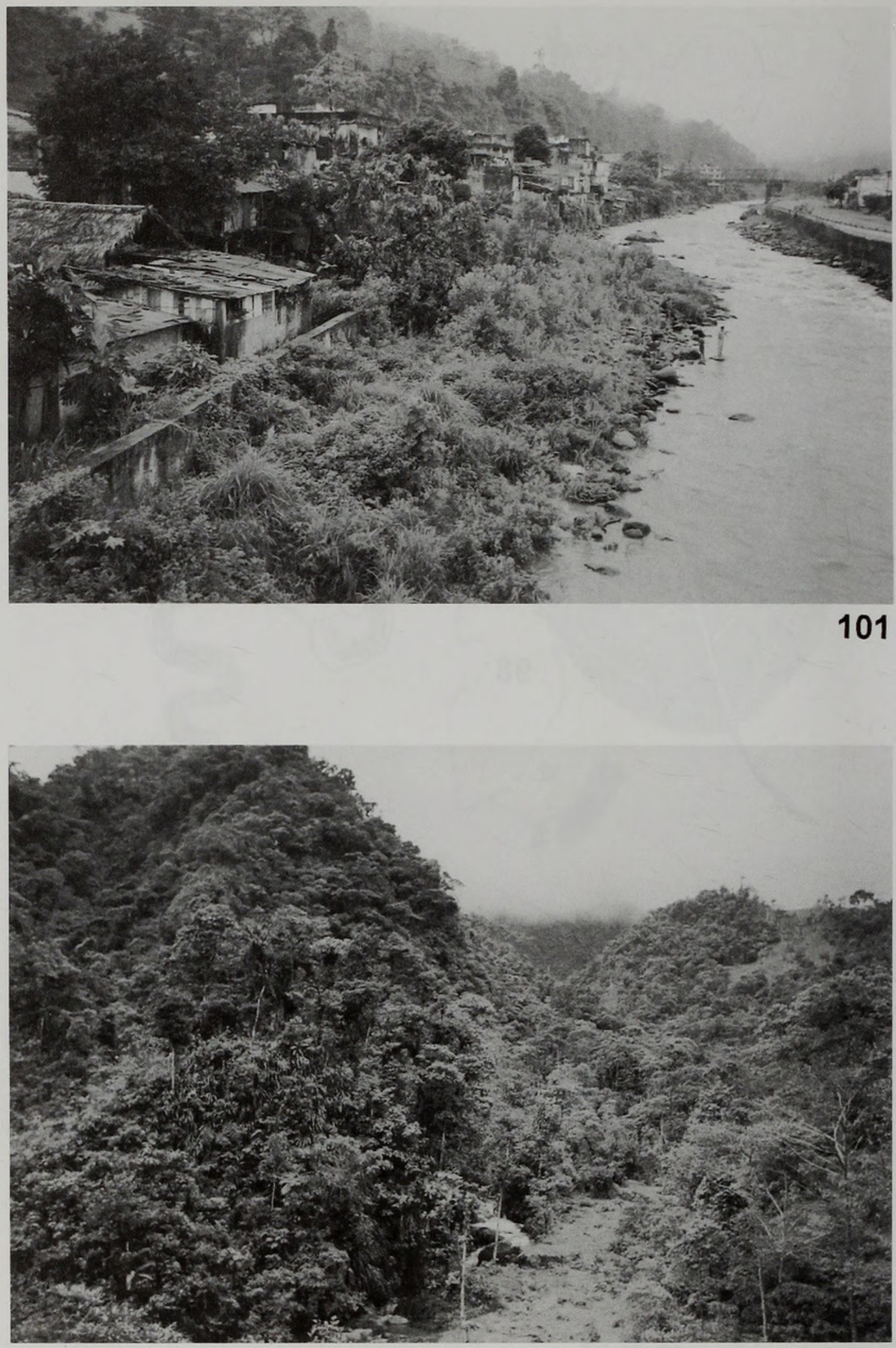

Figs 101, 102. Habitats of species. 101, Enteucha guajavae, western foothills of Andes, $700 \mathrm{~m}$ Bucay (=Cumanda); 102 , Stigmella montanotropica, western slopes of Andes, 1200 m, Tandapi. 


\section{$2 \mathrm{BHL}$ Biodiversity Heritage Library}

Puplesis, Rimantas, Diskus, Arunas, and Robinson, Gaden S. 2002. "New Neotropical Nepticulidae (Lepidoptera) from the western Amazonian rainforest and the Andes of Ecuador." Bulletin of the Natural History Museum. Entomology series 71, 19-58. https://doi.org/10.1017/S0968045402000020.

View This Item Online: https://www.biodiversitylibrary.org/item/127032

DOI: https://doi.org/10.1017/S0968045402000020

Permalink: https://www.biodiversitylibrary.org/partpdf/76405

\section{Holding Institution}

Natural History Museum Library, London

\section{Sponsored by}

Natural History Museum Library, London

\section{Copyright \& Reuse}

Copyright Status: In copyright. Digitized with the permission of the rights holder.

Rights Holder: The Trustees of the Natural History Museum, London

License: http://creativecommons.org/licenses/by-nc-sa/4.0/

Rights: http://biodiversitylibrary.org/permissions

This document was created from content at the Biodiversity Heritage Library, the world's largest open access digital library for biodiversity literature and archives. Visit BHL at https://www.biodiversitylibrary.org. 